\title{
THE PERSISTENCE OF MALADAPTIVE MEMORY: ADDICTION, DRUG MEMORIES AND ANTI-RELAPSE TREATMENTS
}

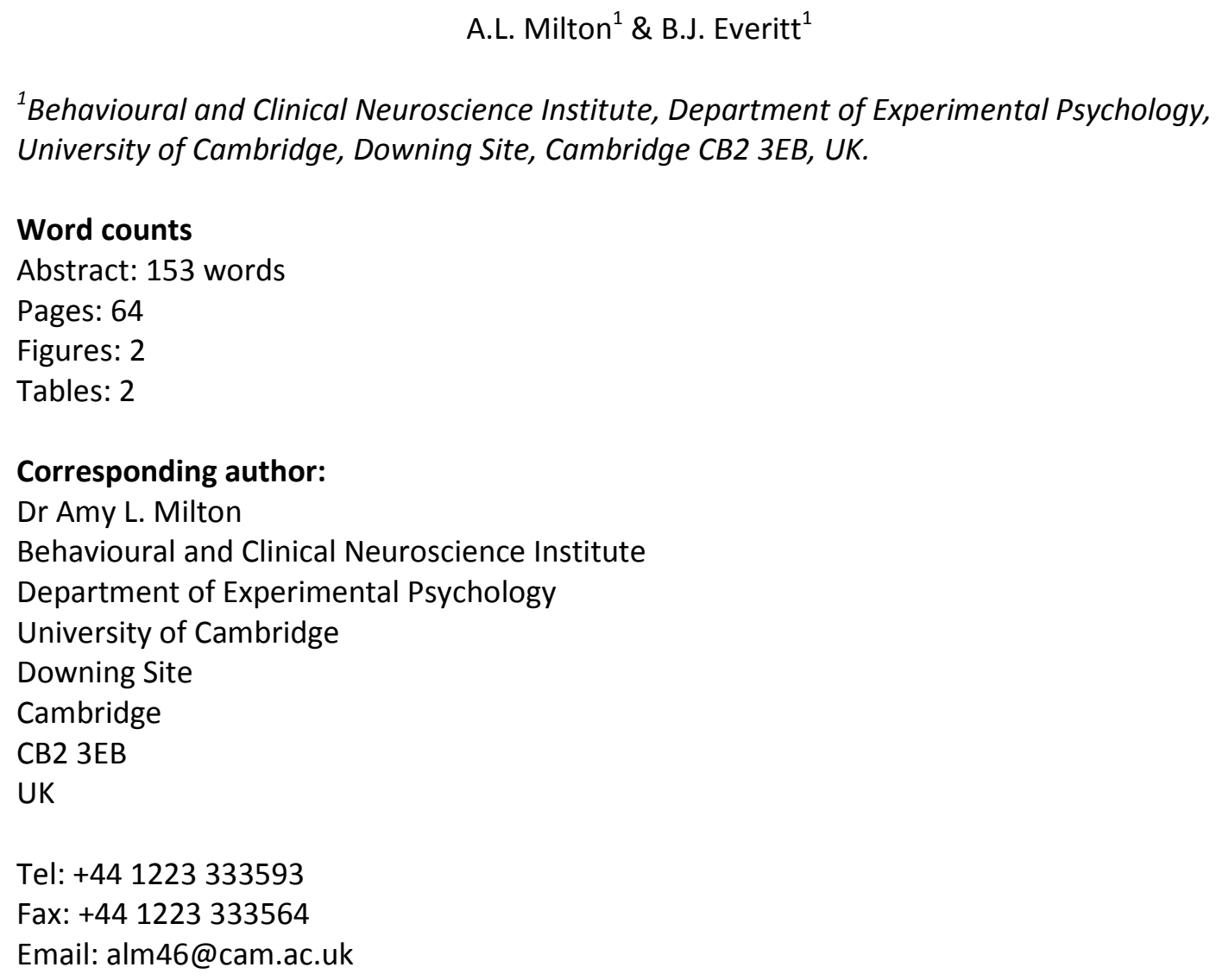




\section{ABSTRACT}

MILTON, A.L. and Everitt, B.J. The persistence of (maladaptive) memory: addiction, drug memories and anti-relapse treatments. NEUROSCI BIOBEHAV REV X(X): XXX-XXX, 2012. Addiction is a chronic, relapsing disorder, characterised by the long-term propensity of addicted individuals to relapse. A major factor that obstructs the attainment of abstinence is the persistence of maladaptive drug-associated memories, which can maintain drug-seeking and taking behaviour and promote unconscious relapse of these habits. Thus, addiction can be conceptualised as a disorder of aberrant learning: of the formation of strong instrumental memories linking actions to drug-seeking and taking outcomes that ultimately are expressed as persistent stimulus-response habits; of previously neutral environmental stimuli that become associated with drug highs (and/or withdrawal states) through pavlovian conditioning, and of the subsequent interactions between pavlovian and instrumental memories to influence relapse behaviour. Understanding the psychological, neurobiological and molecular basis of these drug memories may produce new methods of pro-abstinence, anti-relapse treatments for addiction.

Keywords: addiction, drug, memory, reconsolidation, pavlovian, instrumental 


\section{INTRODUCTION}

Addiction, from the Latin addicere ('to sentence'), is a chronic, relapsing disorder that is problematic for both the individual and society. Drug addiction incurs high social and economic costs, placing major demands on policing and medical resources. In the UK, the cost of harm from Class A drug use was estimated at $\mathrm{f15.4}$ billion in 2003-04 (Gordon et al., 2006). This considerable expense would be significantly reduced by implementing successful treatment programmes; for example, it has been estimated that if all heroin addicts complied with methadone treatment, the UK government would save $f 3-4$ billion over 5 years (Cave and Godfrey, 2006). Addiction is synonymous with the term 'substance dependence' in the Diagnostic and Statistical Manual of Mental Disorders (DSM-IVR) and the International Statistical Classification of Diseases and Related Health Problems (ICD10; Table 1). Both recognise drug addiction when an individual shows loss of control over drug taking behaviour, persistence of drug-taking behaviour despite negative consequences, and high motivation to take the drug at the expense of other activities.

Addiction can be analysed and conceptualised at several levels, from the psychological to the molecular biological. This article reviews addiction with a focus on how it can be conceptualised as a disorder of maladaptive memory, considering the psychological and neural basis of addictive drug-associated memories ( $\$ 2$ and $\S 3$ ) before discussing how pharmacological manipulation of these memories could be used to treat addiction (§4). A major problematic aspect of addiction, both clinically and for the individual, is its chronic and relapsing nature, with the propensity to relapse persisting long after the more obvious signs of acute withdrawal have abated (Gawin and Kleber, 1992). Treatments based on the disruption of drug memory reconsolidation, or facilitated extinction of drug memories, unlike currently available therapies, would target the memories that underlie the disorder to diminish the propensity to relapse long into abstinence (\$5). 


\section{PSYCHOLOGICAL ASSOCIATIONS UNDERLYING ADDICTION}

\subsection{Drug addiction can be viewed as the aberrant engagement of normal learning processes, leading to the formation of persistent maladaptive memories}

The long-term propensity of an addict to relapse suggests that it is not solely acute drug withdrawal effects, such as those found in abstinent opiate addicts (Wikler, 1948) that maintain drug use, but rather that persistent changes in brain function occur, ultimately leading to a prolonged risk of relapse following initial detoxification. One theory of addiction (Everitt et al., 2001; Everitt and Robbins, 2005) hypothesises that the long-term propensity to relapse reflects the formation of drug-associated memories that can not only maintain drug-seeking and drug-taking behaviour while the addict is abusing the drug, but also can precipitate drug-seeking behaviour following a period of abstinence. This theory emphasises that learning processes can account for the long-term risk of relapse in addicts, since these maladaptive memories can be remarkably persistent (Di Ciano and Everitt, 2004a).

This conceptualisation of addiction as the aberrant engagement of normal learning processes makes psychological and neurobiological studies of learning and motivation relevant to addiction research. Everitt, Dickinson \& Robbins (2001) argued that the aberrant engagement of pavlovian and instrumental learning mechanisms, due perhaps to the ability of drugs of abuse to increase dopamine release in parts of the limbic cortico-ventral striatal system, leads to enhanced learning about the actions and environmental, drug-associated cues or conditioned stimuli (CSs) that predict opportunities for drug self-administration. Consequently, these CSs acquire an increasing role in controlling drug seeking behaviour. With repeated drug-taking, the dorsal striatum becomes progressively more engaged by the CSs that have been previously paired with drug self-administration, mediated by the dopaminergic circuitry that links the limbic cortical areas activated by these CSs, including the amygdala, with motor control areas (Figure 1). Therefore, as the state of addiction 
develops, the previously drug-paired CSs come to elicit drug-seeking and taking behaviour, independently of GOAL-DIRECTED ${ }^{1}$ action; drug-seeking and taking become controlled by stimulus-response mechanisms that are habitual and automatic, via CS-induced activation of drug-seeking motor programmes in the dorsal striatum (Belin and Everitt, 2008; Belin et al., 2009). Drug seeking ultimately becomes compulsive, being inflexible, persistent and insensitive to devaluation or PUNISHMENT (Belin and Everitt, 2008; Everitt and Robbins, 2005), reflecting one of the key characteristics of drug addiction, as defined in DSM-IVR and ICD-10 (Table 1). This progression from goal-directed, 'action-outcome' instrumental behaviour to compulsive and HABITUAL 'STIMULUS-RESPONSE' instrumental behaviour, driven by repetition in the presence of pavlovian conditioned stimuli, may reflect a more rapid transition of the normal, adaptive, learning processes that occur with overtraining in working for natural reinforcers. Thus addiction can be viewed as the aberrant engagement of normally adaptive learning processes, which through the content of the underlying associations becomes maladaptive.

\subsection{Specific psychological associations underlying drug addiction}

The associations that form when an individual seeks and takes drugs of abuse are both pavlovian (non-contingent on behaviour) and instrumental (behaviourally contingent) in their nature; whether these are between stimuli in the environment that are present during drug-taking behaviour, or are predictive of drug availability ('stimulus-outcome', or S-O associations), the responses that are necessary to obtain and take the drug ('actionoutcome', or A-O, associations) or, with extensive training, associations between the drugconditioned stimuli and the actions of drug-seeking and-taking ('stimulus-response', or S-R, associations). We will consider these associations and their impact on drug-seeking and relapse behaviour, in turn.

\footnotetext{
${ }^{1}$ See Table 2 for definitions of psychological terms.
} 


\subsubsection{Pavlovian associations}

A pavlovian association is one that develops between a neutral stimulus present within the environment (the 'CONDITIONED STIMULUS', or CS) and a particular consequence (the 'UNCONDITIONED STIMULUS', or US), whether this is an outcome ('S-O' associations) or another stimulus ('S-S' associations; Pavlov, 1927). Importantly, pavlovian associations are independent of the individual's behaviour; the association forms because of the contingency between the CS and the US. However, because PAVLOVIAN CONDITIONING confers incentive motivational value on the previously motivationally neutral CS, the CS can come to support behaviour in its own right, for example by: (i) eliciting a behaviour known as pavlovian CONDITIONED APPROACH (Brown and Jenkins, 1968) as measured in the 'AUTOSHAPING' procedure, where the individual approaches stimuli ('sign-tracking') or locations ('goaltracking') that have previously been paired with REINFORCEMENT; (ii) acquiring reinforcing properties through its association with the outcome, a process known as CONDITIONED REINFORCEMENT (Hyde, 1976; Mackintosh, 1974) and; (iii) influencing the performance of an ongoing instrumental response that has been associated with the same (or sometimes a different) REWARD as the stimulus, a process known as PAVLOVIAN-INSTRUMENTAL TRANSFER (Bindra, 1968; Estes, 1943; Lovibond, 1983). We have reviewed the importance of these three pavlovian processes in addictive behaviour previously (Milton and Everitt, 2010) and so will not discuss them further here. However, in addition to mediating these positive incentive motivational effects, CSs associated with drug can also become associated with the negative incentive motivational effect of CONDITIONED WITHDRAWAL, in addition to conditioned tolerance and conditioned sensitisation. Some influential theories of addiction (Koob and Le Moal, 1997, 2008; Wikler, 1948) particularly emphasise the importance of the conditioned withdrawal association on drug-seeking and drug-taking behaviour, and so this warrants further consideration. 


\subsubsection{Conditioned withdrawal}

Several theories of addiction emphasise the importance of withdrawal in producing negative affective states that elicit craving and maintain drug-seeking behaviour (Koob and Le Moal, 1997; Wikler, 1948) and, as with the positive reinforcing aspects of addictive drug-taking, the negative reinforcing aspects of withdrawal can undergo pavlovian conditioning. The original, still influential, theory of Wikler (1948) proposed that repeated pairings of stimuli present during withdrawal from opiates could lead to the conditioned elicitation of withdrawal symptoms; thus, the presentation of previously withdrawal-associated CSs could produce withdrawal responses as a CONDITIONED RESPONSE. In this way, environmental CSs predictive of withdrawal could support the development of withdrawal-like symptoms (including negative affect), and promote further drug use to alleviate these symptoms, a form of NEGATIVE INSTRUMENTAL REINFORCEMENT (see \$2.2.2.2). There is debate over the relative importance of conditioned withdrawal on relapse behaviour (Lyvers, 1998; McAuliffe, 1982) because physiological withdrawal is relatively short-lived compared to lifetime relapse risk, and because it is difficult to demonstrate experimentally that conditioned withdrawal increases drug-seeking behaviour, due to concurrent withdrawal-induced response suppression (Goldberg and Schuster, 1967; Miller et al., 1979; Wikler and Pescor, 1967). However, several studies support the existence of conditioned withdrawal effects (Childress et al., 1984; O'Brien et al., 1976; Schnur, 1992; Wikler and Pescor, 1967) and, coupled with negative reinforcement (\$2.2.2.2) conditioned withdrawal could act to influence drugseeking and drug-taking behaviour.

\subsubsection{Conditioned tolerance and sensitisation}

Tolerance is the progressive reduction in the effects of a specific dose of drug following repeated administration, and it can be manifest behaviourally as an increase in the amount of drug taken in order to achieve the same subjective and behavioural effect. Tolerance to drug effects is also one of the seven diagnostic criteria for substance abuse in the DSM-IVR 
definition of addiction (Table 1). It can be contrasted to drug sensitisation, in which the response to the drug of abuse increases with repeated administration.

The psychological mechanisms underlying tolerance have been the subject of debate within the addiction and pain literature, particularly concerning whether tolerance is learned or simply a neuroadaptation to the acute but frequently occurring neurochemical effects of the abused drug. 'Opponent-process' theories (Solomon and Corbit, 1974) argue that drug withdrawal and drug tolerance are related neuroadaptations, because while withdrawal symptoms reflect the sudden change in activity of an adapted homeostatic system following the rapid removal of the drug from that system, tolerance reflects the reduced response of the same system in the presence of the drug (Siegel, 1977). Evidence supporting these theories has come largely from studies using morphine as the drug of abuse (Mucha et al., 1979) although 'opponent-process' theories of addiction have also been convincingly argued to apply to psychostimulants, although in a more generalised, hedonic form in which negative affective (hedonic) states, rather than physical signs, are the motivating force (Koob and Le Moal, 1997).

An alternative view is that tolerance reflects learning, whether associative (pavlovian) or non-associative (habituation). Habituation is a form of non-associative learning in which the response to a stimulus reduces following repeated, unreinforced presentations of that stimulus. Baker \& Tiffany (1985) argue that tolerance can be viewed as habituation, generated through expectancy of a drug's effect and so accounting for the contextual specificity of tolerance. Alternatively, tolerance may be a form of 'self-generated priming', in which previous experience with the drug primes an expectancy of the drug's effect, which Baker \& Tiffany (1985) argue accounts for tolerance where there is no obvious context or CS associated with the drug. This could account for the development of apparent 
'drug opposite' effects in contexts in which the drug is expected but not administered (Stewart et al., 1984).

Alternatively, tolerance may be conditioned (Siegel, 1975) rather than nonassociative. There is extensive evidence that tolerance can be influenced by CSs and contexts, particularly when morphine is the drug of abuse (Adams et al., 1969; Ferguson et al., 1969; Kayan et al., 1969). Tolerance shares a number of characteristics with learned associations, such as sensitivity to latent inhibition procedures (Siegel, 1977), and disruption by the administration of agents that prevent learning, such as antagonists at NMDA receptors (Trujillo and Akil, 1991). Furthermore, tolerance to drug effects can be reduced if the association between the drug and the environment is behaviourally extinguished prior to testing (Siegel, 1977). Whether associative or non-associative, or both, drug tolerance can influence the magnitude of drug-seeking and taking behaviour by reducing the physical and/or hedonic effects of drug administration.

Sensitisation seems, at first glance, to be the opposite of drug tolerance: sensitisation is the enhancement of the acute effects of drug administration, usually measured in terms of its effects on locomotor activity. As for drug tolerance, there has been debate in the literature concerning the psychological and neurobiological basis of sensitisation, which may not be a unitary phenomenon (Wise and Leeb, 1993). There is clear evidence that sensitisation can be conditioned (Badiani et al., 1997; Badiani et al., 2000; Vezina and Leyton, 2009), and that this conditioning depends upon dopaminergic transmission in the amygdala and nucleus accumbens (Pert et al., 1990). Sensitisation to the incentive motivational effects of drugs is the basis of another influential theory of addiction (Robinson and Berridge, 1993, 2000), which emphasises the importance of increased attention towards drug stimuli; this increase in attention to drug CSs has been observed for individuals addicted to nicotine (Clarke and Kumar, 1983; Hakan and Ksir, 1988; Stolerman et 
al., 1973), opiates (De Vries et al., 1998; Lubman et al., 2000; Marinelli et al., 1998), cocaine (De Vries et al., 1998; Morgan and Roberts, 2004; Post et al., 1981; Reith, 1986; Shippenberg and Heidbreder, 1995) and amphetamine (Anagnostaras et al., 2002; Badiani et al., 1997; Camp and Robinson, 1988). Certainly, it has been argued that conditioned sensitisation can, in animals, increase the likelihood of subsequent drug-seeking behaviour (Piazza et al., 1990) and conditioned place preference (Shippenberg and Heidbreder, 1995). However, though an amphetamine sensitisation treatment regimen facilitates the formation of habitual responding for food (Nelson and Killcross, 2006; Nordquist et al., 2007) and promotes the escalation of cocaine-seeking (Ferrario and Robinson, 2007), several studies have indicated that behavioural, particularly locomotor, sensitisation is dissociable from subsequent 'addiction-like' phenomena in preclinical models of the disorder, particularly compulsive drug use (Ahmed and Cador, 2006; Belin et al., 2008; Molander et al., 2011). The importance of conditioned sensitisation for addiction is, therefore, still a matter of debate, and a key question that remains to be answered is how tolerance or sensitisation processes come to dominate in a given context. One view (Belin et al., 2011; Belin et al., 2008) is that susceptibility to locomotor sensitisation reflects sensation-seeking, and so the risk of initiating drug use, while trait impulsivity predicts compulsive drug use.

\subsubsection{Instrumental associations}

INSTRUMENTAL, Or OPERANT, CONDITIONING depends upon the consequences of an action to modify the likelihood of that action occurring in the future (Skinner, 1938; Thorndike, 1911). This distinguishes it from pavlovian conditioning, in which the contingency between the CS and the US is independent of the individual's behaviour. Reinforcement of the instrumental response can occur through the learning of either positive or negative consequences of an action, and it is critically dependent on the contingency between the response and the reinforcer, the temporal contiguity between the response and the reinforcer, and the magnitude of reinforcement (Mackintosh, 1974). With extended training, the probability of 
emitting the instrumental response can become independent of the outcome of the action, at which point the behaviour is deemed 'habitual'. Habitual behaviour is hypothesised to be dominated by stimulus-response (S-R) representations, where the likelihood of eliciting the instrumental behaviour is determined by the presence of environmental CSs that were present when the action was learned (Dickinson, 1985), not the outcome of the action. Habitual behaviour can become compulsive, in that it is constantly repeated, even in the face of punishing or aversive outcomes; one of the key criteria of the DSM-IVR definition of substance abuse. In rodent models, compulsive behaviour can be assessed by actively punishing the drug-seeking response, for example, by presenting a CS associated with an aversive outcome, or by pairing some drug-seeking responses with footshock instead of drug (Belin et al., 2011; Belin et al., 2008; Everitt et al., 2008; Everitt and Robbins, 2005; Pelloux et al., 2007; Vanderschuren and Everitt, 2005). Animals that show compulsive drug-seeking behaviour will continue to make drug-seeking responses despite the negative consequences (see §2.2.2.3).

In summary, the initiation of drug-seeking and drug-taking behaviours, and relapse to these behaviours following abstinence, occurs through both positive and negative instrumental reinforcement, both of which are goal-directed. With extended experience drug-seeking and drug-taking can become compulsive and habitual (see §2.2.2.4). Thus, relapse becomes an automatic process elicited by the unconsciously perceived influence of drug-associated CSs.

\subsubsection{Positive reinforcement}

If the outcome of an instrumental response increases the likelihood of that behaviour recurring, then it is termed a 'POSITIVE REINFORCER'. The capacity of addictive drugs to act as effective positive reinforcers does not necessarily mean that they are highly rewarding (Joseph et al., 2003), although in the early stages of addiction there may be a correlation 
between rewarding and reinforcing efficacy. According to the incentive sensitisation theory of addiction (Robinson and Berridge, 1993) there may be a dissociation between the neural systems underlying reward and reinforcement, designated as a difference between 'liking' and 'wanting' systems. Within this theory, a drug outcome could act as a powerfully strong reinforcer by activating the 'wanting' system, without having any effect on the 'liking' system and so not eliciting any hedonic response. Robinson and Berridge (1993) suggest that this is one of the characteristics of the later stages of addiction, which is highly compatible with the activation of compulsive, habitual responding in the maladaptive conditioning theories, where the action of drug-seeking becomes dissociated from the goal of experiencing the drug high (Everitt et al., 2008).

\subsubsection{Negative reinforcement}

Negative reinforcement occurs when the performance of an instrumental response decreases the likelihood of presentation of an aversive stimulus, or removes it, if it is already present in the environment. Therefore, as with positive reinforcement, the performance of the instrumental response increases; negative reinforcement should not be confused with PUNISHMENT (\$2.2.2.3).

Many addiction theories (Koob and Le Moal, 1997; Wikler, 1948) emphasise the importance of negative reinforcement in maintaining drug-seeking behaviour, and this form of 'avoidance learning' is closely linked to conditioned withdrawal (§2.2.1.1). Animals will work to avoid opiate withdrawal symptoms (Goldberg et al., 1971; Hellemans et al., 2006a; Kenny et al., 2006), though it has been suggested that the relative importance of negative reinforcement on relapse behaviour decreases as the individual completes drug detoxification in the early stages of abstinence. However, one way in which negative reinforcement may continue to control drug-seeking behaviour is via 'incentive learning' (Dickinson and Balleine, 1994), which has been shown to undergo consolidation and 
reconsolidation within the amygdala (Wang et al., 2005; see §4). Incentive learning refers to the finding that negative reinforcement only becomes important in maintaining drug-seeking behaviour once an individual has experienced the withdrawal-relieving effects of drugtaking; namely, the individual must have undergone incentive learning that, for example, heroin is a more effective positive reinforcer in the withdrawn state than in the nonwithdrawn state (Hutcheson et al., 2001). Hence, combined with conditioned withdrawal effects, it may be that negative reinforcement can maintain drug-seeking behaviour in the longer term, by 'self-medicating' the negative affective state of conditioned withdrawal or negative hedonic states. As stress produces a negative hedonic state, negative reinforcement may also link learning processes to the well-documented phenomenon of stress-induced relapse (Goeders and Guerin, 1994; Ramsey and Van Ree, 1993).

\subsubsection{Punishment}

Punishment reduces instrumental behaviour, as presentation of the negative outcome is contingent upon behaviour. This distinguishes it from negative reinforcement, in which the frequency of the instrumental response is increased by the removal of an aversive stimulus following the elicitation of the response.

Many of the traditional social responses to addiction are based upon punishment. However, consistent with the hypothesis of addiction involving habitual, compulsive drugseeking and drug-taking that is dissociated from the outcome of the instrumental action, punishment does not seem effectively to deter addicted individuals from drug use, at least in the long term. This has been empirically noted, as one of the key criteria for addiction in DSM-IVR is that the individual persists in drug-seeking and drug-taking behaviour despite adverse consequences (Table $\mathbf{1}$ ) and therefore, by definition addicted individuals will be less likely to modify their behaviour when threatened with prison or other punishments. 
For this reason, punishment has been largely ineffective in helping individuals to relinquish their addiction, though it is likely to be effective at deterring casual users from drug use. Recent work has used this clinical criterion of addiction to derive more realistic animal models for addiction (Deroche-Gamonet et al., 2004; Economidou et al., 2009; Pelloux et al., 2007). In these animal models, individuals are allowed to seek or take cocaine before being screened on a number of behavioural criteria, including the capacity of punishment such as footshock delivery, to reduce drug-seeking or taking. In all of these studies, approximately $15-20 \%$ of individuals were found to be resistant to punishment, which is similar to the proportion of humans who, having been exposed to cocaine, are estimated to be vulnerable to addiction and, therefore, who take drugs despite negative consequences (Anthony et al., 1994). These animals are no less responsive to shock, and do not show persistent seeking of natural reinforcers such as sucrose; therefore, it is argued that this resistance to punishment models compulsive drug-seeking or taking behaviour (Pelloux et al., 2007).

\subsubsection{Stimulus-response associations ('habits')}

Positive reinforcement, negative reinforcement, and punishment are all examples of influences on instrumental action-outcome (A-O) associations since by altering an outcome, the instrumental behaviour is adjusted (e.g. responding more for a bigger and better positive reinforcer, or less when an outcome is devalued by punishment). These may be of greatest relevance for casual drug use, before habitual and compulsive responding for drug emerge (Everitt and Robbins, 2005). S-R associations will also form with behaviours associated with obtaining natural reinforcement (Dickinson, 1985) but usually take extensive 'overtraining' or situations in which a weak contingency between the action and its outcome is operating (for instance, interval schedules) in order to develop. The critical difference between natural reinforcers and addictive drugs has been suggested to be that addictive drugs bias instrumental responding away from mediation by A-O associations, towards S-R 
representations. In addition to Everitt \& Robbins (2005), Cardinal et al. (2002), Berke \& Hyman (2000) and Hyman \& Malenka (2001) have independently hypothesised that drugs of abuse bias individuals towards habitual responding, specifically via the dopamine-dependent 'stamping in' of drug-associated memories. According to this view, the release of dopamine in the targets of ventral tegmental neurons is a signal of prediction error in associative learning for natural reinforcers, and these increases in dopamine promote the plasticity associated with learning (Schultz et al., 1997). Addictive drugs and drug-associated cues consistently increase dopamine release in limbic and striatal structures (Carboni et al., 1989; Di Chiara and Imperato, 1988; Hurd and Ungerstedt, 1989; Kalivas and Duffy, 1990; Kuczenski and Segal, 1989), and thus it is hypothesised that the prediction error signal is always engaged during drug-taking behaviour, promoting pavlovian and habit learning (Redish et al., 2007; Wise, 2002).

This dependence of instrumental behaviour on S-R associations is significant for several aspects of addiction, including persistence of the behaviour despite adverse consequences, and the compulsive nature of drug-seeking. Firstly, because the S-R association does not incorporate a representation of the outcome, S-R associations are persistent despite changes in the value of the outcome, for example, when devalued. Secondly, because the drug-seeking response is elicited by environmental stimuli, S-R behaviour is no longer under the direct control of the motivational state of the individual, and instead is more dependent upon CSs present in the environment. The presentation of these CSs can automatically elicit drug-seeking behaviour that is divorced from the consequences of that behaviour and possibly elicited unconsciously (Tiffany, 1990).

Habitual responding is not necessarily compulsive. Compulsive responding may be operationally defined as habitual behaviour that is constantly repeated despite negative consequences, insensitive to the devaluation of outcome and inflexible following changes in 
the reinforcement schedule (Vanderschuren and Everitt, 2005). In short, while habits are automatic, involuntary behaviours that can be elicited by environmental stimuli, a compulsive habit is one in which the individual feels an urge that the behaviour must be performed, perhaps even despite its consequences. The emergence of compulsive habits has been hypothesised to be a key final stage event in the establishment of addictive drugseeking and taking (Everitt and Robbins, 2005). There is clear evidence from the rat literature that responding for addictive drugs, most notably cocaine, becomes both habitual and compulsive following extended access to the drug. Rats that have extensive cocaine (though not heroin - McNamara et al., 2010) self-administration histories are more likely to continue drug-seeking behaviour in the presence of conditioned stimuli that predict punishment (Vanderschuren and Everitt, 2004) or following punishment of the drug-seeking behaviour (Belin et al., 2008; Deroche-Gamonet et al., 2004; Pelloux et al., 2007) than rats that have more limited self-administration histories. Furthermore, there is evidence that habitual responding for both alcohol (Dickinson et al., 2002) and orally self-administered cocaine (Miles et al., 2003) is insensitive to gastric malaise-induced devaluation procedures that will prevent responding for natural reinforcement such as sucrose, clearly demonstrating that the response of drug-seeking had become independent of its outcome (though it was not demonstrated in these studies that responding had become compulsive). It has also been shown that while rats with limited cocaine self-administration histories are sensitive to devaluation of the 'taking' lever in the 'seeking-taking task' (Olmstead et al., 2001; Zapata et al., 2010), rats with extended self-administration histories are insensitive to devaluation of the taking lever, indicating that drug-seeking behaviour has transitioned from being goal-directed to being habitual (Zapata et al., 2010). Finally, rats with extended cocaine self-administration histories also show inflexible behaviour, as they will continue to show drug-seeking behaviour in the presence of cues that explicitly signal that responding will not be reinforced (Deroche-Gamonet et al., 2004). This can be compared to the human 
situation in which addicted individuals will continue to show inflexible drug-seeking, even when there is the threat of, or actual, punishment of such behaviour.

\subsection{Interim summary}

The formation of drug-associated memories profoundly influences behaviour in addiction, whether those are memories for environmental conditioned stimuli (CSs) associated with the drug, the instrumental actions underlying drug-seeking and drug-taking, or incentive learning that drug use during withdrawal relieves the negative symptoms of that withdrawal or stress. The aberrant engagement of psychological mechanisms normally operating to underlie adaptive behaviour towards natural reinforcers, such as food or sex, can lead to maladaptive, compulsive behaviour by which drugs may become valued above alternative reinforcers, despite the negative consequences of drug abuse. These psychological mechanisms underlying addiction are supported by discrete neurobiological substrates, and treatments for addiction in the future might be more effective if they are based upon not only an understanding of the psychological processes underlying the disorder, but also the areas or systems of the brain and the neurochemical systems that modulate their functioning in consolidating, reconsolidating and extinguishing these drug-related memories.

\section{NEURAL CIRCUITS UNDERLYING ADDICTION}

Although addiction to drugs is associated with changes throughout the brain, one of the key neural systems on which drugs of abuse act is the limbic corticostriatal circuitry, which is involved in motivation, reward, learning and memory. This circuitry is conserved across species, including humans, primates and rodents. Much of the research elucidating the neural circuits underlying addiction has made use of rodent models, which have been used extensively (see Sanchis-Segura and Spanagel, 2008, for review). A full review of the functions of the limbic corticostriatal circuitry is beyond the scope of this article; here we 
focus on the key structures involved in mediating the effects of pavlovian CSs on behaviour, and the circuitry underlying instrumental learning.

\subsection{The 'limbic' corticostriatal circuitry and influences of drug CSs on behaviour}

The limbic corticostriatal system (Figure 1) encompasses 'limbic' cortical sites such as the amygdala and hippocampus, neocortical areas (particularly the prefrontal cortices) and the basal ganglia. The ultimate output of the system is through the basal ganglia (striatum and pallidum), which governs the selection of one action amongst alternatives (Graybiel, 1998; Grillner et al., 2005; Kropotov and Etlinger, 1999; Mink and Thach, 1991).

Among the key neural structures within the limbic corticostriatal circuitry relevant to drug addiction (Figure 1) are the amygdala, the hippocampus, the ventral striatum (including the nucleus accumbens) and the orbitofrontal cortex. Therefore, the general functions of these areas will be discussed, with particular reference to their neurochemical modulation (particularly by dopamine) and their importance for the psychological processes underlying addiction (see §2).

\subsubsection{The amygdala and hippocampus mediate CS-US and context-US associations}

Drug-associated CSs and contexts influence drug-seeking behaviour and relapse by maintaining drug-seeking and drug-taking behaviours, and by precipitating relapse in abstinent individuals (Arroyo et al., 1998; de Wit and Stewart, 1981; Glasner et al., 2005; Glautier, 1994; Meil and See, 1997; Robins et al., 1974; Sinha et al., 2000; Tomie, 1996). These drug CSs induce relapse readily in animal models of drug addiction (de Wit and Stewart, 1981; Shaham et al., 2003) and elicit drug craving in human addicts (Bonson et al., 2002; Childress et al., 1999; Garavan et al., 2000; Grant et al., 1996). Furthermore, drug craving in human addicts and presentation of drug CSs to drug-experienced rats elicits functional activity or cellular and molecular changes in the limbic corticostriatal circuitry (Bonson et al., 2002; Boujabit et al., 2003; Childress et al., 1999; Garavan et al., 2000; Grant 
et al., 1996; Schiffer et al., 2009; Thomas et al., 2003; Thomas and Everitt, 2001), suggesting that the neurobiological substrates underlying the motivational impact of drug-paired CSs is conserved across species. The amygdala and the hippocampus are important in mediating these associations.

The nuclei of the amygdala are critical for the representation of pavlovian CS-US associations. The amygdala consists of a number of interconnected subnuclei, often grouped into the corticomedial, central and basolateral divisions, each with different afferent and efferent projections (Pitkänen et al., 1997). The lateral and basolateral nuclei (together, the BLA) receive a number of sensory inputs, both highly processed inputs from the sensory and association cortices, and 'raw' inputs directly from the thalamus, whilst the central nucleus (CeN) receives the thalamic inputs, input from the sensory brainstem and some cortical inputs from the prefrontal and insula cortices (Li et al., 1996; McDonald et al., 1999; Rizvi et al., 1991; Turner and Herkenham, 1991). The involvement of the basolateral and the central amygdala in motivated behaviour has been the subject of extensive investigation, predominantly through the study of pavlovian conditioned fear. Although evidently very different from the appetitive associations that underlie addiction, many of the conclusions from the fear literature are also relevant to appetitive conditioning (Balleine and Killcross, 2006). The amygdala encodes CS affective values via association with the US, with the BLA and $\mathrm{CeN}$ encoding sensory-specific and general motivational aspects of the CS-US association respectively. The corticomedial amygdala is particularly implicated in olfactory learning, but will not be considered further here.

The BLA has been shown to be necessary for the representation of sensory-specific affective CS-US associations (Balleine and Killcross, 2006; Cador et al., 1989; Holland and Gallagher, 2003), while the $\mathrm{CeN}$ is required for more generalised representations of the affective value of a CS. Thus, broadly speaking the BLA is required for sensory-specific 
conditioned reinforcement and specific pavlovian-instrumental transfer (PIT), while the CeN is necessary for general PIT and pavlovian conditioned approach. The BLA is required for representation of the motivational value or sensory specific properties of conditioned reinforcers, for both natural (Blundell et al., 2001; Hatfield et al., 1996; Holland and Gallagher, 2003; Killcross et al., 1997; Lindgren et al., 2003; Schoenbaum et al., 1998; Setlow et al., 2002) and drug reinforcers (Di Ciano and Everitt, 2004a; Fuchs et al., 2005b; Fuchs and See, 2002; Meil and See, 1997; Yun and Fields, 2003), including under second-order schedules of reinforcement (Whitelaw et al., 1996). Lesions (Meil and See, 1997) and inactivation (Kantak et al., 2002) of the BLA prevent the reinstatement of cocaine-seeking behaviour in CS-induced models of relapse. BLA lesions also disrupt the cue-induced reinstatement of heroin-seeking behaviour (Fuchs and See, 2002), demonstrating the importance of the BLA in mediating CS influences on drug-seeking behaviour for different drug classes. Furthermore, the BLA has also been shown to be activated during conditioned, though not acute, withdrawal (Frenois et al., 2005; Lucas et al., 2008), and BLA lesions prevented a CS associated with morphine withdrawal from suppressing ongoing instrumental behaviour (Schulteis et al., 2000). This indicates that the BLA is important for mediating CS-US associations for aversive, as well as appetitive, reinforcers, consistent with its necessity for conditioned fear (Killcross et al., 1997; LeDoux et al., 1986; Maren et al., 1996).

The role of the CeN in drug-seeking behaviour is less well-established, but it is hypothesised that the CeN may be an important neural substrate for the incentive motivational properties of drug CSs, based on its involvement in PIT (Hall et al., 2001a; Holland and Gallagher, 2003) and conditioned approach towards CSs associated with food reinforcement (Parkinson et al., 2000). The capacity of the CeN to influence behaviour on the basis of general motivational state is also supported by evidence that activity in the CeN is required for stress-induced reinstatement (Erb et al., 2001; Ma et al., 2008). The CeN 
appears critical for footshock stress-induced reinstatement of cocaine-seeking (McFarland et al., 2004) and morphine-seeking (Ma et al., 2008), and corticotrophin releasing factor (CRF) receptor antagonists (Erb et al., 2001) or $\alpha_{2}$-adrenergic receptor agonists (Erb et al., 2000; Yamada and Bruijnzeel, 2010) administered into the CeN reduce stress-induced reinstatement.

Context-induced reinstatement of drug-seeking behaviour requires the hippocampus, similar to its role in contextual fear conditioning (Phillips and LeDoux, 1992; Selden et al., 1991). It is well-established that contexts previously associated with drug use can promote relapse to drug-seeking behaviour in human addicts (O'Brien et al., 1992) and in animals with an extensive history of drug self-administration (Bossert et al., 2006; Bossert et al., 2004; Bossert et al., 2007; Crombag et al., 2002; Crombag and Shaham, 2002; Fuchs et al., 2006; Fuchs et al., 2007; Fuchs et al., 2005a; Kearns and Weiss, 2007). In rodent models, inactivation of the dorsal hippocampus prevents the context-induced reinstatement of cocaine seeking (Fuchs et al., 2005) and inactivation of the dorsal hippocampus and BLA in a 'disconnection' procedure also led to a reduction in context-induced reinstatement (Fuchs et al., 2007). It is hypothesised that the hippocampus represents the context as a CS, with the amygdala associating the hippocampal-encoded context with the affective value of the US; this is the case for contextual memories associated with aversive outcomes (Matus-Amat et al., 2007) and appetitive conditioning for natural (Ito et al., 2006) and drug reinforcers (Hitchcott and Phillips, 1997).

\subsubsection{The ventral striatum integrates motivational influences on behaviour}

The ventral striatum, in particular the nucleus accumbens (NAcb), was hypothesised in a now classic paper by Mogenson et al. (1980) to be the site at which affective or motivational information within the 'limbic' structures is integrated with the behavioural output systems; that it provides a 'limbic-motor interface'. This view sees the nucleus accumbens as 
important in mediating the influence of motivational states and pavlovian stimuli on appetitive, including instrumental, behaviour. The NAcb is subdivided into core (NAcbC) and shell (NAcbSh) subregions, which differ in terms of their connectivity and function (Heimer et al., 1991). The NAcbC receives inputs from the amygdala, insula, and the anterior cingulate, prelimbic and orbitofrontal cortices, and projects to the ventral pallidum, while the NAcbSh receives inputs from the amygdala, hippocampus and prefrontal infralimbic cortex, and in addition to the ventral pallidum projects to 'limbic' outputs such as the lateral hypothalamus (Heimer et al., 1997; Zahm, 1999; Zahm and Brog, 1992). The NAcbSh is an atypical area of the striatum (Heimer et al., 1997), and shares a number of characteristics with the central nucleus of the amygdala, including neurochemical modulation and afferent projections, leading to its inclusion within the 'extended amygdala' (Alheid et al., 1998; Alheid and Heimer, 1988). Furthermore, the NAcb shows neuroadaptations following drug experience, particularly changes in glutamatergic signalling (Kalivas et al., 2003; Moran et al., 2005) that are hypothesised to increase the salience of drug-associated CSs and so their impact on behaviour (Kalivas, 2004).

The functions of the NAcbC and NAcbSh are broadly divided, with the NAcbSh providing a conditioned 'vigour' to a response that is directed by the NAcbC (Ito et al., 2004). Supporting this view, the NAcbC has been shown to mediate the effects of cocaineassociated CSs on instrumental behaviour, whilst the NAcbSh mediates so-called unconditioned stimulant drug effects such as locomotor activity (Parkinson et al., 1999) and UNCONDITIONED RESPONSES for non-drug reinforcers, such as ingestion and environmental exploration (Di Chiara et al., 1999; Kelley et al., 2005; Kelley and Berridge, 2002; Meredith et al., 2008). Thus, briefly (see Cardinal et al., 2003; Everitt and Robbins, 2005, for more extensive review) the NAcbC and NAcbSh are required for different influences on pavlovian CSs on behaviour; lesions of the NAcbC lead to deficits in conditioned reinforcement and general PIT (Hall et al., 2001a; Parkinson et al., 1999) while dopamine depletion within the 
NAcbSh produces impairments in the expression of pavlovian conditioned approach (Parkinson et al., 2002) and outcome-specific PIT (Corbit et al., 2001). The necessity of the NAcb subregions for these behaviours depends on the connections to the different nuclei of the amygdala, with the NAcbC and the BLA constituting a functional circuit for conditioned reinforcement as shown by disconnection lesions (Parkinson et al., 1999) and the NAcbSh interacting with the $\mathrm{CeN}$ and the anterior cingulate cortex to support behaviour such as conditioned approach (Parkinson et al., 2000). However, despite these differences, the NAcbC and NAcbSh are interconnected, suggesting that their functions are not fully independent (van Dongen et al., 2005). The NAcbC and NAcbSh are required for different aspects of drug-seeking behaviour, as revealed by studies using, for example, second order schedules of reinforcement. (For a more extensive review of the role of the nucleus accumbens in addiction, refer to Di Chiara, 2002; Kalivas and McFarland, 2003; Robbins and Everitt, 1996).

In second-order schedules of reinforcement, animals respond for drug over long periods of time (delays to reinforcement) and their seeking responses are maintained by drug-associated CSs, acting as conditioned reinforcers. This procedure allows a dissociation of responding mediated by conditioned and unconditioned drug effects, as the drug is only delivered at the end of a seeking period, which is often defined by the passage of time (e.g. a fixed interval; Everitt and Robbins, 2000). Therefore, responding during the first, drugunaffected seeking period is maintained by the presence of drug-associated CSs, and is not confounded by the unconditioned effects of the drug on behaviour, whilst subsequent intervals, following drug delivery, allow a measure of the effect of the self-administered drug on instrumental seeking behaviour (Everitt and Robbins, 2000). Inactivation of the NAcbC, via local antagonism of glutamate receptors or selective lesion, resulted in greatly reduced cocaine-seeking during the first and subsequent intervals of a second-order schedule (Di Ciano and Everitt, 2001), but with no effect on cocaine-taking under continuous 
reinforcement, suggesting that the NAcbC supports the capacity of conditioned reinforcers to maintain previously acquired drug-seeking behaviour. Furthermore, only NAcbC inactivation, not NAcbSh inactivation, reduced the reinstatement of drug-seeking behaviour by cocaine-associated CSs (Di Ciano et al., 2008; Fuchs et al., 2004). CS-evoked drug-seeking behaviour depends critically upon the connections of the $\mathrm{NAcbC}$ to the basolateral amygdala, as disconnection of the BLA and the NAcbC prevented drug-associated CSs from influencing drug-seeking behaviour (Di Ciano and Everitt, 2004b).

Therefore, the connections between the NAcb and the amygdala form two types of functional circuit; one in which the general affective properties of a pavlovian CS can influence behaviour, depending upon the connection between the $\mathrm{CeN}$ and NAcbC (Hall et al., 2001; Parkinson et al., 1999; Parkinson et al., 2000b) and another that is required for sensory-specific CS-US representations to flexibly influence behaviour, depending upon the connection between the BLA and the NAcbC.

\subsubsection{The dorsal striatum is recruited as drug-seeking becomes a stimulus-response} habit

As described previously (\$2.2.2.) instrumental associations can be either goal-directed (action-outcome, or A-O) or habitual (stimulus-response, or S-R). The learning of A-O and S-R associations depends upon different neural substrates; the prelimbic cortex and anterior dorsomedial striatum for $\mathrm{A}-\mathrm{O}$ associations, and the infralimbic cortex and posterior dorsolateral striatum for S-R associations. (A full discussion of the role of the striatum in learning and addiction is beyond the scope of this review; see Balleine et al., 2009, and other articles in the same special issue for further information.)

Action-outcome behaviour depends upon a circuit encompassing the prelimbic region of prefrontal cortex (Balleine and Dickinson, 1998; Corbit and Balleine, 2003) and the dorsomedial striatum (Yin et al., 2005), along with other areas involved in the representation 
of outcomes predicted by pavlovian stimuli, for example, the orbitofrontal cortex and basolateral amygdala (Baxter et al., 2000; Gallagher et al., 1999; Schoenbaum et al., 1998; Schoenbaum and Esber, 2010). By contrast, habitual behaviour depends critically upon the posterior dorsolateral striatum (Packard and McGaugh, 1996; Yin et al., 2006; Zapata et al., 2010). Though separable, these neural circuits can operate in parallel, and it has been hypothesised (Mishkin et al., 1984) that during the early stages of instrumental learning, the cortex is necessary for the acquisition of instrumental responding but that following extensive training, the instrumental behaviour becomes habitual and more dependent on the dorsal striatum. This is a key component of the maladaptive conditioning theory of addiction (Everitt and Robbins, 2005).

Instrumental behaviour becomes increasingly more dependent on the dorsal striatum with extensive training (Knowlton et al., 1996; Yin et al., 2004) perhaps, it has been hypothesised (Everitt et al., 2008; Everitt and Robbins, 2005) via progressive recruitment by the spiralling dopaminergic circuitry of the midbrain (Haber et al., 2000; Figure 1). Both antagonism of dopamine receptors within the dorsal striatum with $\alpha$-flupenthixol and, separately, inactivation of the dorsal striatum with an AMPA/kainate receptor antagonist disrupts well-established drug-seeking behaviour in rats (Vanderschuren et al., 2005). Furthermore, disconnection of the spiralling dopaminergic circuitry via a combined unilateral lesion of the $\mathrm{NACbC}$ and a contralesional infusion of a dopamine receptor antagonist into the dorsal striatum reduced drug-seeking behaviour in rats that had previously undergone extensive cocaine self-administration training (Belin and Everitt, 2008). The strongest evidence supporting this hypothesis comes from the work of Zapata et al. (2010), which demonstrated that not only did extended training on a seeking-taking chain schedule for cocaine lead to habitual behaviour (measured by the failure to devalue the drug-taking response through contingency degradation) but also that transient inactivation of the posterior dorsolateral striatum reduced drug-seeking only when the drug-taking response 
had been devalued. Although it has been argued that dopaminergic transmission within the dorsolateral striatum may be involved in drug reinforcement (Veeneman et al., 2012), much evidence (Belin and Everitt, 2008; Murray et al., 2011; Vanderschuren and Everitt, 2005; Zapata et al., 2010) suggests that there is a progressive recruitment of the dorsal striatum in mediating drug-seeking behaviour as it becomes habitual and compulsive.

\subsection{Interim summary}

Structures such as the amygdala and hippocampus process sensory and 'limbic' inputs, thereby allowing them to represent the sensory properties of drug-associated CSs and contexts respectively, with the amygdala mediating the motivational value of a particular CS. Projections from the amygdala and hippocampus to the nucleus accumbens core and shell subregions allows for these pavlovian CSs to influence instrumental behaviour, with separate but overlapping neural circuits underlying the psychological processes of conditioned reinforcement, pavlovian conditioned approach and pavlovian-instrumental transfer, all of which contribute to drug-seeking and taking. The development of habitual drug-seeking behaviour is associated with an increasingly dominant control by the dorsal striatum, which may be recruited by antecedent processing in limbic cortical-NAcbC circuitry (Everitt and Robbins, 2005).

\section{DRUG MEMORY RECONSOLIDATION: MECHANISMS AND IMPLICATIONS FOR TREATMENT}

As discussed in §2, the formation of addictive drug memories reflects the usurping of the learning and plasticity processes that normally underlie the learning of associations between environmental stimuli and natural reinforcers. The consolidation of drug-associated memories and the plasticity associated with addiction has been reviewed previously (Hyman 
et al., 2006; Jones and Bonci, 2005; Kauer, 2004). The focus of this section will be on the neurochemical and molecular mechanisms of drug memory reconsolidation.

\subsection{Memory reconsolidation: an introduction}

The traditional and dominant view of memory is that it is stable and immutable following its initial consolidation (McGaugh, 1966). However, this view was challenged by the discovery of 'cue-dependent amnesia' (Misanin et al., 1968; Schneider and Sherman, 1968), in which previously consolidated memories were found to be susceptible to disruption if amnestic agents were given in conjunction with memory retrieval. Following two prominent failures to replicate the finding of cue-dependent amnesia (Dawson and McGaugh, 1969; Gold and King, 1972), this research area was relatively quiescent until reawakened by Nader and colleagues in the early part of this century. Nader et al. (2000) showed that presentation of a pavlovian, fear-associated CS, in conjunction with infusions of the protein synthesis inhibitor anisomycin directly into the basolateral amygdala, led to the disruption of the fear memory long after the memory had consolidated. Furthermore, the amnesia was dependent upon memory reactivation achieved by presentation of the CS, and was persistent. Subsequently, this led to the evolution of the 'cue-dependent amnesia' hypothesis (Lewis, 1979) into the 'memory reconsolidation' hypothesis (Nader, 2003). Memory reconsolidation theories posit, like memory consolidation theories, that following memory consolidation the memory enters a stable state that is persistent, and not susceptible to disruption. However, in contrast to memory consolidation theories, the reconsolidation hypothesis states that the consolidated memory can return to a short-lived, labile state through retrieval of that memory. Therefore, a memory cycles between 'active' and 'inactive' states depending upon whether it has recently been retrieved (Nader, 2003), when it enters the 'active state' (Lewis, 1979). 
The molecular and neurochemical mechanisms of memory reconsolidation have been reviewed previously (Milton and Everitt, 2010; Tronson and Taylor, 2007) and so will not be considered further in detail here. Instead, we will focus on evidence that the pavlovian and instrumental associations discussed in $\S 3$ reconsolidate.

\subsection{Pavlovian drug memory reconsolidation}

Studies of drug memory reconsolidation have almost exclusively focused on the reconsolidation of the pavlovian memories that underlie the maintenance of drug-seeking, and the long-term propensity to relapse. These associations can be assessed in rodents through many different behavioural procedures which model the psychological processes of conditioned reinforcement, CONDITIONED MOTIVATION, conditioned approach and conditioned withdrawal either in isolation, or in combination. In isolating specific psychological processes, these procedures allowed a greater understanding of the association in memory that is undergoing reconsolidation, both in terms of the animal's predicted behaviour if amnesic, and in terms of neural substrates. However, these tasks, inspired by animal learning theory, are not fully representative of the clinical context in which drug memories influence the addiction cycle, and so it is advantageous to combine these psychologically specific tasks with others that translate more readily to addiction and relapse in a clinical population.

\subsubsection{Pavlovian CS-drug memories assessed using conditioned place preference (CPP)}

Conditioned place preference (CPP) is a widely used procedure used to measure the motivational properties of addictive drugs. In this procedure, the rats receive experimenteradministered injections of drug, and are confined in the 'paired' compartment of a two- or three-compartment apparatus. On alternate training sessions, the animals are injected with an equivalent volume of saline, and are placed in the 'unpaired' compartment of the apparatus. Training typically requires 8 injections in total ( 4 drug and 4 saline). The drug- 
conditioned place preference is subsequently assessed by allowing the rats to move throughout the whole apparatus, with the time spent on the paired and unpaired sides being used to assess the reinforcing properties of the drug.

This procedure is quickly and easily learned, though it has some interpretational constraints. Firstly, it is not clear which psychological processes underlie place preference at test: a preference for the paired side could be supported by a number of learned associations, and it is not clear how all of these contribute to the expression of the preference. The second difficulty of interpretation in conditioned place preference procedures is the reliance on experimenter-administered drugs, which does not model the instrumental drug self-administration characterising addictive drug use in humans. Furthermore, because of the small number of pairings between the addictive drug and the paired side in the conditioned place preference procedure, this does not reflect the extent of pavlovian conditioning that occurs between environmental conditioned stimuli and the effects of drug in human addicts, who have an extensive history of drug use and therefore many pairings of CS and US.

Despite these interpretational challenges, the CPP procedure has been used extensively and successfully to investigate the neurochemical basis of drug memory reconsolidation. One of the original demonstrations that drug memories reconsolidate used this procedure; Miller and Marshall (2005) demonstrated that the administration of an inhibitor of the intracellular protein kinase ERK (extracellular signal-regulated kinase) in conjunction with memory retrieval, could prevent the expression of a place preference previously conditioned to cocaine at subsequent tests, conducted $24 \mathrm{hrs}$ and 14 days following the treatment. Since this original demonstration, it has been established that the memories underlying conditioned place preference for drugs other than cocaine also reconsolidate, including CS-amphetamine (Sadler et al., 2007) and CS-morphine (Milekic et 
al., 2006; Robinson and Franklin, 2007a, b, 2010; Valjent et al., 2006) memories, both of which are susceptible to disruption with amnestic agents.

The reconsolidation of the memories underlying drug CPP depends upon protein synthesis (Milekic et al., 2006; Robinson and Franklin, 2007b; though see also Yim et al., 2006) and the activation of intracellular signalling cascades, such as those mediated via extracellular signal-related kinase (ERK; Valjent et al., 2006). These are, in turn, most likely activated by signalling at glutamatergic and adrenergic receptors, as the reconsolidation of the memory association(s) underlying CPP is blocked by the administration of either NMDAR antagonists (Brown et al., 2008; Itzhak, 2008; Itzhak and Anderson, 2007; Sadler et al., 2007; Zhai et al., 2008) or $\beta$-adrenergic receptor antagonists (Bernardi et al., 2006; Bernardi et al., 2009; Fricks-Gleason and Marshall, 2008; Robinson and Franklin, 2007) in conjunction with memory reactivation. Most studies of CPP memory reconsolidation have relied on the systemic administration of amnestic agents, though reconsolidation of these memories has been shown to depend more specifically on $\beta$-adrenergic signalling in the BLA (Bernardi et al., 2009), ERK-mediated signalling in the NAcbC (Miller and Marshall, 2005) and expression of the plasticity-related immediate early gene, zif268, in the basolateral amygdala and the nucleus accumbens core (Théberge et al., 2010). zif268 is expressed following memory retrieval (Hall et al., 2001b; Thomas et al., 2003; Thomas et al., 2002) and has been extensively implicated in the reconsolidation process (Bozon et al., 2003; Hellemans et al., 2006; Lee, 2008; Lee et al., 2005; Lee et al., 2004).

\subsubsection{Pavlovian CS-drug memories assessed by isolating psychological associations}

Like the memories underlying drug CPP, the memories underlying the capacity of cocaine CSs to act as conditioned reinforcers, measured through the 'acquisition of a new instrumental response' procedure (Mackintosh, 1974), depend upon protein synthesis and the expression of zif268 within the BLA (Lee et al., 2005). The expression of zif268 required 
for the reconsolidation of CS-cocaine memories is driven by signalling at NMDARs, since antagonism at NMDARs with D-APV prevents not only the CS from acting as a conditioned reinforcer subsequently, but also reduces the expression of Zif268 protein within the BLA (Milton et al., 2008a). This requirement for zif268 activity to promote the reconsolidation of the memory underlying conditioned reinforcement is restricted to the BLA, since knockdown of zif268 in other structures, such as the nucleus accumbens core (NAcbC), in conjunction with memory reactivation had no subsequent effect on the conditioned reinforcement memory (Théberge et al., 2010). Note, however, that the memories underlying CPP, and those specifically underlying conditioned reinforcement have different requirements for zif268 signalling during reconsolidation.

Though much of the work investigating the reconsolidation of specific psychological processes related to pavlovian memories has focused on conditioned reinforcement, there is some evidence that the CS-drug memories underlying conditioned motivation and conditioned approach also reconsolidate. The reconsolidation of CS-alcohol memories underlying conditioned approach as measured in an autoshaping procedure, and conditioned motivation as measured by pavlovian-instrumental transfer (PIT) depend upon signalling at the NMDAR, but not signalling at $\beta$-adrenergic receptors (Milton et al., 2011). The independence from $\beta$-adrenergic receptor signalling mechanisms of reconsolidation for the pavlovian associations underlying conditioned motivation and conditioned approach is very different from the disruption of the reconsolidation of the memory underlying conditioned reinforcement with the $\beta$-adrenergic receptor antagonist propranolol, for both CS-cocaine (Milton et al., 2008b) and CS-alcohol (Schramm et al., unpublished results) memories.

Finally, although there has been much less investigation of the reconsolidation of conditioned withdrawal and conditioned sensitisation, there is evidence that these 
associations also reconsolidate. It has been demonstrated that the memories underlying conditioned withdrawal reconsolidate within the BLA in a zif268-dependent manner (Hellemans et al., 2006) and that the reconsolidation of the memory underlying contextually-conditioned locomotor sensitisation to cocaine can be disrupted by the administration of anisomycin in conjunction with retrieval (Bernardi et al., 2007). To date, no work has been conducted on the reconsolidation of the memories underlying conditioned tolerance. This is a research area that warrants further investigation, especially with regard to incentive learning about drugs of abuse.

\subsubsection{Pavlovian CS-drug memories assessed via translational 'relapse' models}

There are two translationally relevant models of drug CS-induced relapse that have been used extensively in drug addiction research: 'extinction-reinstatement' (de Wit and Stewart, 1981) and reinstatement following enforced abstinence (Lu et al., 2005; Shaham et al., 2003). These are procedurally similar in that animals are trained to make an instrumental response to receive (usually intravenous) drug and presentations of a pavlovian CS. Following training, animals either undergo extinction training, in which instrumental responses are not reinforced with the drug or the CS, or 'enforced abstinence', in which they are not returned to the operant chamber for a specified length of time. Following these manipulations, the animals are subsequently tested for the reinstatement of instrumental responding when the drug $\mathrm{CS}$, though not the drug, are once again made contingent upon instrumental responding.

Typically, disruption of CS-drug memory reconsolidation as assessed in these models does not impair the instrumental responding for drug itself - the 'action-outcome' association - but rather, it reduces the ability of the drug CS to maintain and enhance instrumental responding. This reduction in CS-maintained instrumental responding has been observed following several different manipulations at reactivation, including zif 268 
knockdown with antisense oligodeoxynucleotides (Lee et al., 2006a), PKA inactivation (Sanchez et al., 2010), NMDAR antagonism (Milton et al., 2008a; von der Goltz et al., 2009) though, interestingly, not $\beta$-adrenergic receptor antagonism for cocaine memories (Milton and Everitt, 2009), though $\beta$-adrenergic receptor antagonism at retrieval of alcohol cues does appear to reduce subsequent CS-elicited drug-seeking for alcohol (Wouda et al., 2010). These differences may reflect the differential dependence of behavioural procedures used to model addiction on the processes of conditioned reinforcement, conditioned motivation and conditioned approach. As these pavlovian 'routes to relapse' depend upon the BLA and CeN to differing degrees (see Milton and Everitt, 2010, for review), we hypothesise that the apparent discrepancies in the effects of $\beta$-adrenergic receptor antagonism on drug memory reconsolidation may be due to differences in $\beta$-adrenergic receptor expression across the BLA and CeN.

\subsection{Instrumental drug memory reconsolidation}

Compared to studies of pavlovian memory reconsolidation, there is little published work on the reconsolidation of instrumental memories. This can be attributed, at least in part, to an influential paper that reported that instrumental memories do not reconsolidate (Hernandez and Kelley, 2004). However, instrumental behaviour can be mediated through either goaldirected, action-outcome associations, or habitual stimulus-response associations (Dickinson, 1985); both of which depend upon different neural circuitry. Therefore, disruption of one association underlying instrumental behaviour would not necessarily lead to a subsequent reduction in that behaviour at test; if, for example, the reconsolidation of a stimulus-response association was disrupted, habitual behaviour might be reduced, but if the animal still valued the outcome, then the action-outcome association might compensate for the disrupted S-R association. It is therefore important to distinguish between these associations when attempting to disrupt their reconsolidation. 
One method of distinguishing between behaviour mediated via action-outcome associations and stimulus-response associations is to design a test in which the two types of behaviour are dissociable. Packard and McGaugh (1996) used such a procedure, training rats to run to a sucrose-reinforced arm in a T-maze. This behaviour could be supported by an action-outcome association that depended on the location of the sucrose in space - a 'place' representation - or by a stimulus-response association through which the sucrose was located relative to the start arm. By rotating the maze $180^{\circ}$, it is possible to separate the responses mediated by each representation (Figure $\mathbf{2 a}$ ). As would be predicted from theoretical perspectives on habit learning (Dickinson, 1985), limited training produced behaviour that was primarily driven by an action-outcome association, with more extensive, overtraining producing an increased reliance on stimulus-response associations. Packard \& McGaugh (1996) also demonstrated that the action-outcome representation required activity in the dorsal hippocampus, while stimulus-response associations required activity in the posterior dorsolateral striatum, consistent with other studies of the neural basis of 'habitual' S-R behaviour (Yin et al., 2004).

Retrieval of the stimulus-response memory in the T-maze procedure was associated with an increase in the expression of Zif268 (Figure 2b; Milton et al., unpublished results). Animals were trained extensively on the T-maze task over 14 days, and subsequently given a probe test in which the maze was rotated 24 hours after the last training session. Brains were harvested either 2 or 6 hours later, and assessed for expression of Zif268 in four striatal regions. This analysis revealed that animals that had shown the S-R associationmediated behaviour in the probe test had increased levels of Zif268 expression specifically in the posterior dorsolateral striatum relative to animals showing the $\mathrm{A}-\mathrm{O}$ associationmediated behaviour at test. This increase was evident in the brains that had been harvested 2 hours following the probe test, but not for those collected 6 hours following the probe test. This is consistent with previous studies showing that the knockdown of Zif268 
expression 6 hours following memory retrieval does not prevent reconsolidation (Lee et al., 2006a). Other striatal areas (including the anterior dorsomedial striatum) did not show a reliable increase in Zif268 expression (Figure $\mathbf{2 b}$ ). While correlative, these preliminary results suggest that, like pavlovian memories (Hall et al., 2001b; Thomas et al., 2002), the expression of zif268 increases following the retrieval of at least one type of instrumental memory. Whether Zif268 is required for the reconsolidation of S-R habit memories, as it is for the reconsolidation of pavlovian memories (Bozon et al., 2003; Hellemans et al., 2006; Lee et al., 2005; Lee et al., 2004; Lee et al., 2006a; Théberge et al., 2010), clearly warrants further study.

\subsection{Interim summary}

The disruption of memory reconsolidation may provide a new form of therapy for treating drug addiction. To date, most of the preclinical work has focused upon disrupting pavlovian CS-drug associations, so as to reduce their propensity to precipitate relapse and to maintain drug-seeking behaviour. These drug CSs are remarkably persistent and resistant to extinction (Di Ciano and Everitt, 2004a), so disruption of the 'three routes to relapse' through targeting reconsolidation should provide a method for reducing the risk of relapse in the long term (Milton and Everitt, 2010).

Less studied has been the disruption of the reconsolidation of the S-R memories that underlie drug-seeking in the later stages of the disorder. If drug-seeking behaviour could be returned to being goal-directed following an extensive drug self-administration history, then this would represent a major step forward in the treatment of drug addiction; this could potentially allow long-term drug addicts to once again gain control of their behaviour. Should this be possible, then abstinent addicts should be able to use legal drugs (e.g. alcohol) recreationally without a lapse converting into a full relapse; something that has been very difficult to achieve with currently available treatments for addiction. 


\section{ALTERNATIVE TREATMENT STRATEGIES FOR ADDICTION}

Understanding the psychological and neural mechanisms underlying addiction should ultimately lead to the development of treatments for the disorder. However, though they work with some success, the current therapies available for addiction - pharmacotherapy and behavioural treatments - do not target one of the major underlying causes of addiction, namely, the maladaptive associations that underlie the propensity to seek and take drug, or to relapse following abstinence. Treatments based upon the disruption of drug memory reconsolidation or, perhaps, the enhancement of drug memory extinction, could provide a means by which these memories could be disrupted, and the risk of relapse markedly reduced.

\subsection{Comparison to existing treatment strategies}

Treatments for addiction have been in development since the disorder was first recognised, ranging from Sigmund Freud's unsuccessful attempts to treat morphine addiction with the administration of cocaine (reviewed in Streatfeild, 2007) to maintenance-harm reduction treatments such as methadone or nicotine patches, and behavioural treatments such as cognitive behavioural therapy (CBT). The methods of action of currently available treatments vary markedly - from managing symptoms to providing coping strategies - but unlike the proposed reconsolidation-based treatments, none of the currently available treatments have ever attempted to disrupt the maladaptive memory associations that underlie relapse.

One interesting novel type of treatment, however, aims to reduce the impact of CS-drug memories on behaviour by facilitating and generalising their extinction; this will also be considered in this section.

\subsubsection{Medication-based therapies}

Substitution therapies are one of the most widely used methods to reduce harm in addiction, by maintaining individuals on a safe and clean drug supply that provides an 
alternative treatment to establish abstinence. These can take the form of either drug replacement therapies which are designed to reduce withdrawal symptoms, such as methadone and buprenorphine for opiate addiction, or nicotine patches for cigarette smokers, or medications to reduce the anxiety or anhedonia associated with drug withdrawal, as in the case of treating cocaine-dependent subjects early in withdrawal with antidepressants (McElroy et al., 1989). Drug replacement therapies have shown success in preventing relapse, particularly to drugs associated with a physiological withdrawal syndrome on the cessation of use.

Another way in which medication-based therapy can be applied to the treatment of addiction is to reduce 'craving' for drugs of abuse. A number of compounds, including agonists at $G A B A_{B}$ receptors and antagonists at the $D_{3}$ subtype of dopamine receptor, are in preclinical development as anti-craving treatments (Brebner et al., 2002; Di Ciano et al., 2003; Economidou et al., 2011; Pilla et al., 1999; Tyacke et al., 2010) and may provide a way of reducing self-administration of psychostimulants. Clinical trials of compounds targeting $D_{3}$ dopamine receptors are underway (see Heidbreder and Newman, 2010, for review). Furthermore, the $\mu$ opiate receptor antagonist naltrexone has been used successfully to reduce craving for a number of drugs of abuse in the clinical situation. Naltrexone has been shown to reduce CS-induced reinstatement to alcohol-seeking behaviour (Liu and Weiss, 2002), to reduce 'binge drinking' (Ji et al., 2008; Simms et al., 2008) in rodent models of alcoholism, and to prevent lapses from escalating into relapses in abstinent human alcoholics (Rösner et al., 2008). Naltrexone has also been shown to prevent craving for cocaine: it has been shown to reduce CS-induced (Burattini et al., 2008) and cocaine-induced (Gerrits et al., 2005) reinstatement of cocaine-seeking in rats, in addition to reducing cocaine self-administration in monkey and rodent models (Corrigall and Coen, 1991; Mello et al., 1990). This suggests that drugs active at $\mu$ opiate receptors, such as naltrexone, may have potential as a more general 'anti-craving' drug, rather than specifically reducing craving to a 
particular drug of abuse (e.g. varenicline reducing craving for nicotine - see Foulds et al., 2006, for review).

An alternative use of medication in preventing relapse to drug addiction has been to induce an aversive state; for instance, the use of disulfiram in treating alcoholics. Disulfiram induces a profound sensitivity to the negative effects of alcohol by blocking the action of the liver enzyme acetaldehyde dehydrogenase (Deitrich and Erwin, 1971). As acetaldehyde is a major contributor to the 'hangover' symptoms (e.g. flushing of the skin, accelerated heart rate, nausea, vomiting) felt after excessive intake of alcohol, disulfiram effectively induces a 'hangover' state rapidly (5-10 minutes) after the intake of alcohol, that can last from 30 minutes to several hours. Disulfiram is thus effectively a punishment for alcohol intake, inducing a central aversive state. However, as discussed previously (\$2.2.2.4.) habitual behaviour mediated by S-R associations is insensitive to devaluation; therefore, it might be predicted that the devaluation of alcohol with disulfiram in compulsive, habitual alcoholics would be ineffective in reducing drug-seeking, just as devaluation of a food reinforcer with overfeeding or the induction of gastric malaise with lithium chloride is ineffective at reducing habitual food-seeking. Thus, the treatment of addiction via punishment of drug-seeking and -taking behaviour has generally not been shown to be successful in human addicts or animal models (Pelloux et al., 2007) and the negative effects of disulfiram are usually insufficient to prevent relapse to alcohol self-administration in human addicts (Krampe et al., 2006).

Medication-based treatments for addiction, though showing some success, face some difficulties. Firstly, all require long-term treatment compliance to be effective, and this is often difficult to achieve with individuals being treated for addiction on an outpatient basis due to issues of patient retention and medication compliance (Kampman et al., 2006). This is particularly problematic with medications that have undesirable side effects (even if these are central to the treatment, as for disulfiram) because this reduces the motivation of 
the individual to continue with the treatment. However, even if medication compliance was possible to achieve, there are a further two challenges that a reliance on medication-based therapies would produce. One is the expense of maintaining addicts on the medication, and the other is that the regular use of medication would perpetuate the 'drug addict' image, continuing the stigmatisation associated with addiction. These negatives could be avoided by directly targeting the maladaptive CS-drug memories.

\subsubsection{Behavioural therapies}

A number of behavioural therapies are available for the treatment of addiction, including individual- (contingency management, cognitive behavioural therapy, extinction therapy) and group-based therapies (multidimensional family therapy, the "12 steps"). Here we will focus on individual-based therapies.

\subsubsection{Contingency management}

Contingency management is a type of behavioural therapy that has shown moderate success. Under this scheme addicts are rewarded for maintaining abstinence by, for example, receiving shopping vouchers in return for drug-free urine samples (Higgins et al., 1991). Contingency management has been demonstrated to reduce drug use for cocaine (Petry et al., 2004), heroin (Silverman et al., 1996) and marijuana (Budney et al., 2000), at least in the short-term. It has been noted (Carroll and Onken, 2005) that contingency management is limited by a number of factors, including the weakening of its effects following the end of the treatment. Coupled to the high costs of providing the incentives that underlie this treatment, a long-term maintenance on contingency maintenance therapy would be difficult. This type of therapy is also unpopular with the general public, as reflected by the responses to the introduction of contingency management as a therapy for drug addiction in the UK National Health Service (McCrae, 2007). 
Contingency management was introduced as an alternative to the 'punishment' approach (prison and enforced detoxification) of treating addiction, which has been more traditionally favoured by society. However, there is a 'substantial proportion' of addicts who do not respond to contingency management as a form of therapy (Carroll and Onken, 2005). This may be because contingency management does not work on those that already show increased time spent in pursuit of drug in comparison to other natural and social reinforcers, as is part of the criteria for substance dependence according to DSM-IV and ICD-10 (Table 1). In these users there may be a short term effect of novelty of the shopping voucher reinforcer, but this will ultimately become degraded in comparison to the reward of the addictive drug, as did other aspects of the individual's life as the addiction developed. As with other addiction therapies, contingency management does not treat the underlying cause of the addiction, and in a number of addicts is not effective at all (Carroll and Onken, 2005).

\subsubsection{Cognitive behavioural therapy}

Cognitive behavioural therapy (CBT) is designed to help addicts recognise, avoid and cope with situations in which they are most likely to use drugs. Part of the procedure is based on the theories of Tiffany (1990) as addicts are taught consciously to monitor their behaviour in order to avoid the execution of the 'automatic' behaviour of drug-taking. The avoidance of situations in which the addict is likely to take drug is based upon the knowledge that environmental CSs and contexts increase the probability of drug-seeking and drug-taking behaviour, whether through the induction of 'craving' or the direct activation of the limbiccorticostriatal circuitry involved in compulsive drug-seeking and drug-taking behaviour. Certainly it appears that cognitive behavioural therapy can have effects on the limbic corticostriatal circuitry, as when it is used to treat clinical depression, functional imaging studies show that the activity of the corticolimbic circuitry is modulated similarly to the effects of anti-depressant drugs (Goldapple et al., 2004). 
A subset of cognitive behavioural therapy is extinction or 'exposure' therapy, in which addicted individuals are presented with environmental cues that have previously been paired with the opportunity to self-administer drug, but are no longer reinforced during therapy (O'Brien et al., 1990). This type of treatment is informed by the preclinical literature: 'extinction' therapies aim to achieve the devaluing of the CS-drug association by degrading the reinforcement contingency, creating a competing 'CS-no drug' association, so that CSs will no longer elicit compulsive drug-seeking behaviour (or 'craving'). However, it has been commented (Conklin and Tiffany, 2002; Torregrossa et al., 2010) that extinction therapies generally do not take into account the highly context-specific nature of extinction learning (Bouton, 2002; Bouton and Swartzentruber, 1991). Memory extinction is hypothesised to be context specific, whereas the original, conditioned association is not (Bouton and Bolles, 1979), and therefore the original association will tend to reinstate following exposure to novel contexts or the context in which the original association was trained (Bouton and Bolles, 1979) as well as spontaneously recovering over time (Brooks and Bouton, 1993; Pavlov, 1927). Findings of reinstatement and renewal are common in the animal learning literature, meaning that the benefits of this type of therapy tend to be limited to the clinical context and are not sustained in the outside world (Conklin and Tiffany, 2002). Though cueexposure therapy has been applied to addiction with limited success (see Conklin and Tiffany, 2002, for review), there is scope for improvement (Nic Dhonnchadha and Kantak, 2011; Torregrossa et al., 2010).

\section{2. 'Facilitated extinction' techniques}

Much work has focused on facilitating the formation and generalisation of extinction memories using pharmacotherapy; for instance, the NMDAR partial agonist D-cycloserine (DCS). DCS potentiates extinction learning in rodent models (Ledgerwood et al., 2003; Lee et al., 2006b; Walker et al., 2002) and may enhance the generalisation of extinction learning. In rats conditioned to fear a CS in two different contexts, extinction in one context under DCS 
reduced freezing not only in the extinguished context, but also in an alternative, nonextinguished context (Ledgerwood et al., 2005), suggesting that the administration of DCS may produce a generalisation of extinction that would overcome the difficulties of using 'cue-exposure' therapies in the clinic, particularly the phenomena of renewal and reinstatement. Indeed, in a small clinical trial of height-phobic patients, administration of DCS in conjunction with virtual reality exposure to heights reduced fear for at least 3-months following the treatment (Davis et al., 2006).

D-cycloserine has also been applied to rodent models of addiction. DCS facilitates the extinction of a place preference previously conditioned to cocaine (Thanos et al., 2009) or alcohol (Groblewski et al., 2009). DCS has also been shown to enhance the extinction of instrumental alcohol-seeking behaviour in a rodent extinction-reinstatement model (Vengeliene et al., 2008), though it is difficult to generalise these findings to the clinical situation, where human addicts do not make unreinforced instrumental drug-seeking and drug-taking responses as part of their therapy. More straightforward to translate to the clinic is the finding that drug-CS extinction, in a preclinical behavioural procedure designed to model human cue exposure therapy, is facilitated by DCS, and reduces subsequent instrumental drug-seeking behaviour in both the extinction context, and a non-extinguished alternative context (Torregrossa et al., 2010). However, the behavioural parameters used in conjunction with DCS are extremely important; when given in conjunction with short cue reexposure sessions, DCS facilitates the reconsolidation of the CS-drug memory (Lee et al., 2009), i.e. will actually strengthen the memory, thus potentially worsening treatment outcome. This dependence on the extent of the cue re-exposure session may reconcile the apparently conflicting findings that DCS enhances cue-reactivity in cocaine-dependent subjects (Price et al., 2009) while reducing reactivity in nicotine-dependent subjects (Santa Ana et al., 2009). 
Despite the promising results with D-cycloserine, some investigators have suggested that treatments that avoid pharmacotherapy might be more useful in treating addiction. Some recent work suggests that it might be possible to facilitate extinction without the use of psychoactive drugs. It has been found that if extinction learning occurs within a short time 'window' following memory reactivation, there is an apparently persistent amnesia that does not renew, reinstate or spontaneously recover, which is observed at least for fear memories in rodents (Monfils et al., 2009). This facilitated extinction effect is also seen in human subjects trained on a fear conditioning task (Schiller et al., 2010). However, these findings have not always been replicable (Chan et al., 2010) and to date, have not been applied to CS-drug memories, which can be remarkably persistent and resistant to extinction procedures (Di Ciano and Everitt, 2004a).

\subsection{Alternative treatment strategies: comparison to memory-disruption techniques}

There are four obstacles to the development of addiction therapies - (i) patient retention in the programme, including medication compliance, (ii) the expense of long-term maintenance on a treatment programme, (iii) the continued stigmatisation of the addict acting as a barrier towards developing a new, drug-free life, and (iv) the effectiveness of the treatment when the individual returns to environments previously paired with drug-taking behaviour. The first three problems arise primarily out of therapies that attempt to treat the symptoms, and not the underlying causes, of relapse, and the last because of problems in the strength of competing associations compared to the association underlying compulsive drug-taking behaviour. Therapies based upon the disruption of memory reconsolidation or the facilitation of extinction might avoid or minimise most of these obstacles to successful treatment. The medication requirement of reconsolidation-based therapy would be much less than the regular dosing or therapy sessions that are currently required in relapse prevention treatments and, as a reconsolidation-based treatment would not require daily, prophylactic medication of the individual in order to avoid relapse, it should provide a more 
cost-effective solution to the treatment of addiction than substitution therapies or contingency management. The few treatment sessions required - the preclinical literature suggests that the disruption of reconsolidation could occur in as few as one or two sessions should also promote patient retention in the treatment programme, as these sessions could be conducted while the individual was still showing high motivation to discontinue drug use. It could be incorporated into standard cue exposure therapy or cognitive behavioural therapy in a straightforward manner. Reconsolidation-based therapies might also help to prevent the continued stigmatisation of addicts, as there would be fewer outward signs that the individual was undergoing therapy to prevent relapse, such as daily medication or frequent visits to the clinic.

Furthermore, because reconsolidation-based treatments target the CS-drug association directly, it is possible that the therapy would show less context-dependence than standard extinction therapies, although this has yet to be fully verified experimentally and compared to 'facilitated extinction' therapies. It is also necessary to establish the nature of the amnesia obtained with reconsolidation-based treatments, since an amnesia persisting for many months or years would be more clinically useful than an amnesia that lasted for only a few weeks. The specificity of the amnesia to the reactivated memory requires further investigation, though the sole study investigating this issue suggests that only directly reactivated memories undergo reconsolidation (Debiec et al., 2006). The parameters of memory reactivation that are optimal to establish a long-lasting amnesia (Lee and Everitt, 2008) clearly warrant further study, as does the switch between reconsolidation and extinction; this will be very important for ensuring that the intended memory is modulated. Determining whether instrumental memories reconsolidate will also be extremely important for addiction therapy. 


\section{CONCLUSIONS}

Drug addiction is a complex disorder of the nervous system, with potentially a number of subtypes (Redish et al., 2008), depending upon the specific vulnerabilities of the individual and the drug of abuse. However, a most problematic aspect of treating addiction is the longterm propensity of the addict to relapse (Gawin and Kleber, 1992), and this is known to be profoundly influenced by the presentation of drug-associated, environmental conditioned stimuli (Bonson et al., 2002; Boujabit et al., 2003; Childress et al., 1999; Crombag and Shaham, 2002; Garavan et al., 2000; Grant et al., 1996; See, 2002; Volkow et al., 1991). This suggests that relapse to drug-seeking behaviour is influenced by learned associations, and in this sense one way in which it can be conceptualised is as a disorder of aberrantly strong learning that leads to maladaptive behaviours (Everitt et al., 2001; Everitt and Robbins, 2005).

An understanding of the psychological and neurobiological mechanisms underlying addictive behaviour will inform the development of treatments that target these learned associations. One promising form of treatment is that based upon the disruption of memory reconsolidation, the process by which memories become labile and susceptible to disruption following retrieval. Preclinical studies have suggested that even a single session of treatment can lead to the long-term reduction in drug-motivated behaviour, although to date there have been no corroborative human studies. Ultimately, addiction can be conceptualised as a disorder of learning and memory, and an understanding of the molecular and cellular basis of learning within the underlying limbic corticostriatal circuitry should ultimately lead to the development of new therapies for the disorder. 


\section{ACKNOWLEDGMENTS}

This work was supported by a UK Medical Research Council grant (no. 9536855) to BJE, and was conducted in the Behavioural and Clinical Neuroscience Institute, funded by a joint award from the MRC and the Wellcome Trust. Matej Macak and Brian Kelleher provided technical assistance in the collection of the data shown in Figure 2. 


\section{REFERENCES}

Ahmed, S.H., Cador, M., 2006. Dissociation of psychomotor sensitization from compulsive cocaine consumption. Neuropsychopharmacology 31, 563-571.

Alheid, G.F., Beltramino, C.A., De Olmos, J.S., Forbes, M.S., Swanson, D.J., Heimer, L., 1998. The neuronal organization of the supracapsular part of the stria terminalis in the rat: The dorsal component of the extended amygdala. Neuroscience 84, 967-996.

Alheid, G.F., Heimer, L., 1988. New perspectives in basal forebrain organization of special relevance for neuropsychiatric disorders: The striatopallidal, amygdaloid, and corticopetal components of substantia innominata. Neuroscience 27, 1-39.

Anthony, J.C., Warner, L.A., Kessler, R.C., 1994. Comparative epidemiology of dependence on tobacco, alcohol, controlled substances, and inhalants: findings from the National Comorbidity Survey. Experimental \& Clinical Psychopharmacology 166, 244-268.

Arroyo, M., Markou, A., Robbins, T.W., Everitt, B.J., 1998. Acquisition, maintenance and reinstatement of intravenous cocaine self-administration under a second-order schedule of reinforcement in rats: effects of conditioned cues and continuous access to cocaine.

Psychopharmacology 140, 331-344.

Baker, T.B., Tiffany, S.T., 1985. Morphine tolerance as habituation. Psychological Review 92, 78-108.

Balleine, B.W., Dickinson, A., 1998. Goal-directed instrumental action: contingency and incentive learning and their cortical substrates. Neuropharmacology 37, 407-419.

Balleine, B.W., Killcross, S., 2006. Parallel incentive processing: an integrated view of amygdala function. Trends Neurosci. 29, 272-279.

Balleine, B.W., Liljeholm, M., Ostlund, S.B., 2009. The integrative function of the basal ganglia in instrumental conditioning. Behav. Brain Res. 199, 43-52.

Baxter, M.G., Parker, A., Lindner, C.C.C., Izquierdo, A.D., Murray, E.A., 2000. Control of response selection by reinforcer value requires interaction of amygdala and orbital prefrontal cortex. The Journal of Neuroscience 20, 4311-4319.

Belin, D., Berson, N., Balado, E., Piazza, P.V., Deroche-Gamonet, V., 2011. High-noveltypreference rats are predisposed to compulsive cocaine self-administration.

Neuropsychopharmacology 36, 569-579.

Belin, D., Everitt, B.J., 2008. Cocaine seeking habits depend upon dopamine-dependent serial connectivity linking the ventral with the dorsal striatum. Neuron 57, 432-441.

Belin, D., Jonkman, S., Dickinson, A., Robbins, T.W., Everitt, B.J., 2009. Parallel and interactive learning processes within the basal ganglia: relevance for the understanding of addiction. Behav. Brain Res. 199, 89-102.

Belin, D., Mar, A.C., Dalley, J.W., Robbins, T.W., Everitt, B.J., 2008. High impulsivity predicts the switch to compulsive cocaine-taking. Science 320, 1352-1355.

Berke, J.D., Hyman, S.E., 2000. Addiction, dopamine, and the molecular mechanisms of memory. Neuron 25, 515-532.

Bernardi, R.E., Lattal, K.M., Berger, S.P., 2007. Anisomycin disrupts a contextual memory following reactivation in a cocaine-induced locomotor activity paradigm. Behav. Neurosci. 121, 156-163.

Bernardi, R.E., Ryabinin, A.E., Berger, S.P., Lattal, K.M., 2009. Post-retrieval disruption of a cocaine conditioned place preference by systemic and intrabasolateral amygdala $\beta_{2}$ and $\alpha_{1}$ adrenergic antagonists. Learn. Memory 16, 777-789.

Bindra, D., 1968. Neuropsychological interpretation of the effects of drive and incentivemotivation on general activity and instrumental behavior. Psychological Review 75, 1-22. Bouton, M.E., 2002. Context, ambiguity, and unlearning: sources of relapse after behavioral extinction. Biological Psychiatry 52, 976-986. 
Bouton, M.E., Bolles, R.C., 1979. Contextual control of the extinction of conditioned fear. Learn. Motiv. 10, 445-466.

Bouton, M.E., Swartzentruber, D., 1991. Sources of relapse after extinction in pavlovian and instrumental learning. Clinical Psychology Review 11, 123-140.

Bozon, B., Davis, S., Laroche, S., 2003. A requirement for the immediate early gene zif268 in reconsolidation of recognition memory after retrieval. Neuron 40, 695-701.

Brebner, K., Childress, A.R., Roberts, D.C.S., 2002. A potential role for $\mathrm{GABA}_{\mathrm{B}}$ agonists in the treatment of psychostimulant addiction. . Alcohol \& Alcoholism 37, 478-484.

Brooks, D.C., Bouton, M.E., 1993. A retrieval cue for extinction attenuates spontaneous recovery. J. Exp. Psychol.: Anim. Behav. Processes 19, 77-89.

Brown, P.L., Jenkins, H.M., 1968. Auto-shaping of the pigeon's key peck. J. Exp. Anal. Behav. 11, 1-8.

Budney, A.J., Higgins, S.T., Radonovich, K.J., Novy, P.L., 2000. Adding voucher-based incentives to coping skills and motivational enhancement improves outcomes during treatment for marijuana dependence. Journal of Consulting and Clinical Psychology 68, 1051-1061.

Burattini, C., Burbassi, S., Aicardi, G., Cervo, L., 2008. Effects of naltrexone on cocaine- and sucrose-seeking behaviour in response to associated stimuli in rats. International Journal of Neuropsychopharmacology 11, 103-109.

Cador, M., Robbins, T.W., Everitt, B.J., 1989. Involvement of the amygdala in stimulusreward associations: interaction with the ventral striatum. Neuroscience 30, 77-86.

Cardinal, R.N., Parkinson, J.A., Hall, J., Everitt, B.J., 2002. Emotion and motivation: the role of the amygdala, ventral striatum, and prefrontal cortex. Neurosci. Biobehav. Rev. 26, 321-352. Cardinal, R.N., Parkinson, J.A., Hall, J., Everitt, B.J., 2003. The contribution of the amygdala, nucleus accumbens, and prefrontal cortex to emotion and motivated behaviour.

International Congress Series 1250, 347-370.

Carroll, K.M., Onken, L.S., 2005. Behavioral therapies for drug abuse. Am. J. Psychiatry 162, 1452-1460.

Cave, J., Godfrey, C., 2006. Economics of addiction and drugs. . www.foresight.gov.uk/Previous Projects/Brain Science Addiction and Drugs/Reports and Publications/ScienceReviews/Economics.pdf

Chan, W.Y., Leung, H.T., Westbrook, R.F., McNally, G.P., 2010. Effects of recent exposure to a conditioned stimulus on extinction of pavlovian fear conditioning. Learn. Memory 17, 512521.

Clarke, P.B., Kumar, R., 1983. The effects of nicotine on locomotor activity in non-tolerant and tolerant rats. Br. J. Pharmacol. 78, 329-337.

Conklin, C.A., Tiffany, S.T., 2002. Applying extinction research and theory to cue-exposure addiction treatments. Addiction 97, 155-167.

Corbit, L.H., Balleine, B.W., 2003. The role of prelimbic cortex in instrumental conditioning. Behav. Brain Res. 146, 145-157.

Corbit, L.H., Muir, J.L., Balleine, B.W., 2001. The role of the nucleus accumbens in instrumental conditioning: evidence of a functional dissociation between accumbens core and shell. The Journal of Neuroscience 21, 3251-3260.

Corrigall, W.A., Coen, K.M., 1991. Opiate antagonists reduce cocaine but not nicotine selfadministration. Psychopharmacology 104, 167-170.

Davis, M., Ressler, K.J., Rothbaum, B.O., Richardson, R., 2006. Effects of D-cycloserine on extinction: translation from preclinical to clinical work. Biological Psychiatry 60, 369-375.

Dawson, R.G., McGaugh, J.L., 1969. Electroconvulsive shock effects on a reactivated memory trace: further examination. Science 166, 525-527.

de Wit, H., Stewart, J., 1981. Reinstatement of cocaine-reinforced responding in the rat. Psychopharmacology 75, 134-143. 
Debiec, J., Doyere, V., Nader, K., LeDoux, J.E., 2006. Directly reactivated, but not indirectly reactivated, memories undergo reconsolidation in the amygdala. Proceedings of the National Academy of Sciences 103, 3428-3433.

Deitrich, R.A., Erwin, V.G., 1971. Mechanism of the inhibition of aldehyde dehydrogenase in vivo by disulfiram and diethyldithiocarbamate. Mol. Pharmacol. 7, 301-307.

Deroche-Gamonet, V., Belin, D., Piazza, P.V., 2004. Evidence for addiction-like behavior in the rat. Science 305, 1014-1017.

Di Chiara, G., 2002. Nucleus accumbens shell and core dopamine: differential role in behavior and addiction. Behav. Brain Res. 137, 75-114.

Di Chiara, G., Tanda, G., Bassareo, V., Pontieri, F., Acquas, E., Fenu, S., Cadoni, C., Carboni, E., 1999. Drug addiction as a disorder of associative learning: role of nucleus accumbens shell/extended amygdala dopamine. Ann. N. Y. Acad. Sci. 877, 461-485.

Di Ciano, P., Everitt, B.J., 2001. Dissociable effects of antagonism of NMDA and AMPA/KA receptors in the nucleus accumbens core and shell on cocaine-seeking behavior.

Neuropsychopharmacology 25, 341-360.

Di Ciano, P., Everitt, B.J., 2004a. Conditioned reinforcing properties of stimuli paired with self-adminstered cocaine, heroin or sucrose: implications for the persistence of addictive behavior. Neuropharmacology 47, 202-213.

Di Ciano, P., Everitt, B.J., 2004b. Direct interactions between the basolateral amygdala and nucleus accumbens core underlie cocaine-seeking behavior by rats. The Journal of Neuroscience 24, 7167-7173.

Di Ciano, P., Underwood, R.J., Hagan, J.J., Everitt, B.J., 2003. Attenuation of cue-controlled cocaine-seeking by a selective D 3 dopamine receptor antagonist SB-277011-A. .

Neuropsychopharmacology 28, 329-338.

Dickinson, A., 1985. Actions and habits: the development of behavioural autonomy.

Philosophical Transactions of the Royal Society of London B 308, 67-78.

Dickinson, A., Balleine, B., 1994. Motivational control of goal-directed action. Anim. Learn. Behav. 22, 1-18.

Dickinson, A., Wood, N., Smith, J.W., 2002. Alcohol seeking by rats: action or habit? The Quarterly Journal of Experimental Psychology 55B, 331-348.

Economidou, D., Dalley, J.W., Everitt, B.J., 2011. Selective norepinephrine reuptake inhibition by atomoxetine prevents cue-induced heroin and cocaine seeking. Biological Psychiatry 69, 266-274.

Economidou, D., Pelloux, Y., Robbins, T.W., Dalley, J.W., Everitt, B.J., 2009. High impulsivity predicts relapse to cocaine-seeking after punishment-induced abstinence. Biological Psychiatry 65, 851-856.

Erb, S., Hitchcott, P.K., Rajabi, H., Mueller, D., Shaham, Y., Stewart, J., 2000. Alpha-2 adrenergic receptor agonists block stress-induced reinstatement of cocaine seeking. Neuropsychopharmacology 23, 138-150.

Erb, S., Salmaso, N., Rodaros, D., Stewart, J., 2001. A role for the CRF-containing pathway from central nucleus of the amygdala to bed nucleus of the stria terminalis in the stressinduced reinstatement of cocaine seeking in rats. Psychopharmacology 158, 360-365. Estes, W.K., 1943. Discriminative conditioning. 1. A discriminative property of conditioned anticipation. Journal of Experimental Psychology 32, 150-155.

Everitt, B.J., Belin, D., Economidou, D., Pelloux, Y., Dalley, J.W., Robbins, T.W., 2008. Neural mechanisms underlying the vulnerability to develop compulsive drug-seeking habits and addiction. Philosophical Transactions of the Royal Society B 363, 3125-3135.

Everitt, B.J., Dickinson, A., Robbins, T.W., 2001. The neuropsychological basis of addictive behaviour. Brain Res. Rev. 36, 129-138. 
Everitt, B.J., Robbins, T.W., 2000. Second-order schedules of drug reinforcement in rats and monkeys: measurement of reinforcing efficacy and drug-seeking behaviour.

Psychopharmacology 153, 17-30.

Everitt, B.J., Robbins, T.W., 2005. Neural systems of reinforcement for drug addiction: from actions to habits to compulsion. Nat. Neurosci. 8, 1481-1489.

Ferrario, C.R., Robinson, T.E., 2007. Amphetamine pretreatment accelerates the subsequent escalation of cocaine self-administration behavior. European Neuropsychopharmacology 17, 352-357.

Foulds, J., Steinberg, M.B., Williams, J.M., Ziedonis, D.M., 2006. Developments in pharmacotherapy for tobacco dependence: past, present and future. Drug Alcohol Rev. 25, 59-71.

Fuchs, R.A., Eaddy, J.L., Su, Z.I., Bell, G.H., 2007. Interactions of the basolateral amygdala with the dorsal hippocampus and dorsomedial prefrontal cortex regulate drug contextinduced reinstatement of cocaine-seeking in rats. Eur. J. Neurosci. 26, 487-498.

Fuchs, R.A., Evans, K.A., Ledford, C.C., Parker, M.P., Case, J.M., Mehta, R.H., See, R.E., 2005. The role of the dorsomedial prefrontal cortex, basolateral amygdala, and dorsal hippocampus in contextual reinstatement of cocaine seeking in rats.

Neuropsychopharmacology 30, 296-309.

Fuchs, R.A., See, R.E., 2002. Basolateral amygdala inactivation abolishes conditioned stimulus- and heroin-induced reinstatement of extinguished heroin-seeking behavior in rats. Psychopharmacology 160, 425-433.

Gallagher, M., McMahan, R.W., Schoenbaum, G., 1999. Orbitofrontal cortex and representation of incentive value in associative learning. The Journal of Neuroscience 19, 6610-6614.

Gawin, F.H., Kleber, H.D., 1992. Evolving conceptualizations of cocaine dependence, Clinician's Guide to Cocaine Addiction: Theory, Research and Treatment. The Guildford Press, New York, pp. 33-52.

Gerrits, M.A., Kuzmin, A.V., van Ree, J.M., 2005. Reinstatement of cocaine-seeking behavior in rats is attenuated following repeated treatment with the opioid receptor antagonist naltrexone. European Neuropsychopharmacology 15, 297-303.

Glasner, S.V., Overnier, J.B., Balleine, B.W., 2005. The role of pavlovian cues in alcohol seeking in dependent and nondependent rats. J. Stud. Alcohol 66, 53-61.

Glautier, S., 1994. Classical conditioning, drug cues and drug addiction., in: Legg, C.R., Booth, D.A. (Eds.), Appetite: Neural and Behavioural Bases. Oxford University Press, Oxford, UK, pp. 165-193.

Goeders, N.E., Guerin, G.F., 1994. Non-contingent electric footshock facilitates the acquisition of intravenous cocaine self-administration in rats. Psychopharmacology 114, 6370.

Gold, P.E., King, R.A., 1972. Amnesia: tests of the effect of delayed footshock-

electroconvulsive shock pairings. Physiol. Behav. 8, 797-800.

Goldapple, K., Segal, Z., Garson, C., Lau, M., Bieling, P., Kennedy, S., Mayberg, H., 2004.

Modulation of cortical-limbic pathways in major depression: treatment-specific effects of cognitive behavior therapy. Archives of General Psychiatry 61, 34-41.

Goldberg, S.R., Schuster, C.R., 1967. Conditioned suppression by a stimulus associated with nalorphine in morphine-dependent monkeys. J. Exp. Anal. Behav. 10, 235-242.

Gordon, L., Tinsley, L., Godfrey, C., Parrott, S., 2006. The economic and social costs of Class A drug use in England and Wales, 2003/04.

http://rds.homeoffice.gov.uk/rds/pdfs06/rdsolr1606.pdf

Groblewski, P.A., Lattal, K.M., Cunningham, C.L., 2009. Effects of D-cycloserine on extinction and reconditioning of ethanol-seeking behavior in mice. Alcoholism, Clinical and Experimental Research 33, 772-782. 
Haber, S.N., Fudge, J.L., McFarland, N.R., 2000. Striatonigrostriatal pathways in primates form an ascending spiral from the shell to the dorsolateral striatum. The Journal of Neuroscience 20, 2369-2382.

Hakan, R.L., Ksir, C.J., 1988. Nicotine induced locomotor activity in rats: the role of pavlovian conditioning. Pharmacology, Biochemistry, and Behavior 29, 661-665.

Hall, J., Parkinson, J.A., Connor, T.M., Dickinson, A., Everitt, B.J., 2001a. Involvement of the central nucleus of the amygdala and nucleus accumbens core in mediating Pavlovian influences on instrumental behaviour. Eur. J. Neurosci. 13, 1984-1992.

Hall, J., Thomas, K.L., Everitt, B.J., 2001b. Cellular imaging of zif268 expression in the hippocampus and amygdala during contextual and cued fear memory retrieval: selective activation of hippocampal CA1 neurons during the recall of contextual memories. The Journal of Neuroscience 21, 2186-2193.

Heidbreder, C.A., Newman, A.H., 2010. Current perspectives on selective dopamine $D_{3}$ receptor antagonists as pharmacotherapeutics for addictions and related disorders. Ann. $\mathrm{N}$. Y. Acad. Sci. 1187, 4-34.

Heimer, L., Alheid, G.F., de Olmos, J.S., Groenewegen, H.J., Haber, S.N., Harlan, R.E., Zahm, D.S., 1997. The accumbens: beyond the core-shell dichotomy. The Journal of Neuropsychiatry \& Clinical Neurosciences 9, 354-381.

Heimer, L., Zahm, D.S., Churchill, L., Kalivas, P.W., Wohltmann, C., 1991. Specificity in the projection patterns of accumbal core and shell in the rat. Neuroscience 41, 89-125.

Hellemans, K.G.C., Everitt, B.J., Lee, J.L.C., 2006. Disrupting reconsolidation of conditioned withdrawal memories in the basolateral amygdala reduces suppression of heroin seeking in rats. The Journal of Neuroscience 26, 12694-12699.

Hernandez, P.J., Kelley, A.E., 2004. Long-term memory for instrumental responses does not undergo protein synthesis-dependent reconsolidation upon retrieval. Learn. Memory 11, 748-754.

Higgins, S.T., Delaney, D.D., Budney, A.J., Bickel, W.K., Hughes, J.R., Foerg, F., Fenwick, J.W., 1991. A behavioral approach to achieving initial cocaine abstinence. Am. J. Psychiatry 148, 1218-1224.

Hitchcott, P.K., Phillips, G.D., 1997. Amygdala and hippocampus control dissociable aspects of drug-associated conditioned rewards. Psychopharmacology 131, 187-195.

Holland, P.C., Gallagher, M., 2003. Double dissociation of the effects of lesions of basolateral and central amygdala on conditioned stimulus-potentiated feeding and pavlovian-

instrumental transfer. Eur. J. Neurosci. 17, 1680-1694.

Hutcheson, D.M., Everitt, B.J., Robbins, T.W., Dickinson, A., 2001. The role of withdrawal in heroin addiction: enhances reward or promotes avoidance? Nat. Neurosci. 4, 943-947.

Hyde, T.S., 1976. The effect of Pavlovian stimuli on the acquisition of a new response. Learn. Motiv. 7, 223-239.

Hyman, S.E., Malenka, R.C., 2001. Addiction and the brain: the neurobiology of compulsion and its persistence. Nature Reviews Neuroscience 2, 695-703.

Hyman, S.E., Malenka, R.C., Nestler, E.J., 2006. Neural mechanisms of addiction: the role of reward-related learning and memory. Annu. Rev. Neurosci. 29, 565-598.

Ito, R., Robbins, T.W., Everitt, B.J., 2004. Differential control over cocaine-seeking behavior by nucleus accumbens core and shell. Nat. Neurosci. 7, 389-397.

Ito, R., Robbins, T.W., McNaughton, B.L., Everitt, B.J., 2006. Selective excitotoxic lesions of the hippocampus and basolateral amygdala have dissociable effects on appetitive cue and place conditioning based on path integration in a novel Y-maze procedure. Eur. J. Neurosci. 23, 3071-3080.

Ji, D., Gilpin, N.W., Richardson, H.N., Rivier, C.L., Koob, G.F., 2008. Effects of naltrexone, duloxetine, and a corticotropin-releasing factor type 1 receptor antagonist on binge-like alcohol drinking in rats. Behavioural Pharmacology 19, 1-12. 
Jones, S., Bonci, A., 2005. Synaptic plasticity and drug addiction. Curr. Opin. Pharm. 5, 20-25. Joseph, M.H., Datla, K., Young, A.M.J., 2003. The interpretation of the measurement of nucleus accumbens dopamine by in vivo dialysis: the kick, the craving or the cognition? Neurosci. Biobehav. Rev. 27, 527-541.

Kalivas, P.W., 2004. Glutamate systems in cocaine addiction. Curr. Opin. Pharm. 4, 23-29. Kalivas, P.W., McFarland, K., 2003. Brain circuitry and the reinstatement of cocaine-seeking behavior. Psychopharmacology 168, 44-56.

Kalivas, P.W., McFarland, K., Bowers, S., Szumlinski, K., Xi, Z.X., Baker, D., 2003. Glutamate transmission and addiction to cocaine. Ann. N. Y. Acad. Sci. 1003, 169-175.

Kampman, K.M., Dackis, C., Lynch, K.G., Pettinati, H., Tirado, C., Gariti, P., Sparkman, T., Atzram, M., O'Brien, C.P., 2006. A double-blind, placebo-controlled trial of amantadine, propranolol, and their combination for the treatment of cocaine dependence in patients with severe cocaine withdrawal symptoms. Drug Alcohol Depend. 85, 129-137.

Kantak, K.M., Black, Y.D., Valencia, E., Green-Jordan, K., Eichenbaum, H.B., 2002. Dissociable effects of lidocaine inactivation of the rostral and caudal basolateral amygdala on the maintenance and reinstatement of cocaine-seeking behavior in rats. The Journal of Neuroscience 22, 1126-1136.

Kauer, J.A., 2004. Learning mechanisms in addiction: synaptic plasticity in the ventral tegmental area as a result of exposure to drugs of abuse. Annual Review of Psychology 66, 447-475.

Kelley, A.E., Baldo, B.A., Pratt, W.E., Will, M.J., 2005. Corticostriatal-hypothalamic circuitry and food motivation: Integration of energy, action and reward. Physiol. Behav. 86, 773-795. Kelley, A.E., Berridge, K.C., 2002. The neuroscience of natural rewards: relevance to addictive drugs. The Journal of Neuroscience 22, 3306-3311.

Killcross, S., Robbins, T.W., Everitt, B.J., 1997. Different types of fear-conditioned behaviour mediated by separate nuclei within amygdala. Nature 388, 377-380.

Knowlton, B.J., Mangels, J.A., Squire, L.R., 1996. A neostriatal habit learning system in humans. Science 273, 1399-1402.

Koob, G.F., Everitt, B.J., Robbins, T.W., 2008. Reward, motivation and addiction, in: Squire, L.R., Bloom, F.E., Spitzer, N.C., du Lac, S., Ghosh, A., Berg, D. (Eds.), Fundamental

Neuroscience, 3rd edition. Academic Press, Burlington, MA.

Koob, G.F., Le Moal, M., 1997. Drug abuse: hedonic homeostatic dysregulation. Science 278, 52-58.

Krampe, H., Stawicki, S., Wagner, T., Bartels, C., Aust, C., Rüther, E., Poser, W., Ehrenreich, H., 2006. Follow-up of 180 alcoholic patients for up to 7 years after outpatient treatment: impact of alcohol deterrents on outcome. Alcoholism, Clinical and Experimental Research 30 , 86-95.

Ledgerwood, L., Richardson, R., Cranney, J., 2003. Effects of D-cycloserine on extinction of conditioned freezing. Behav. Neurosci. 117, 341-349.

Ledgerwood, L., Richardson, R., Cranney, J., 2005. D-cycloserine facilitates extinction of learned fear: effects on reacquisition and generalized extinction. Biological Psychiatry 57, 841-847.

LeDoux, J.E., Sakaguchi, A., Iwata, J., Reis, D.J., 1986. Interruption of projections from the medial geniculate body to an archi-neostriatal field disrupts the classical conditioning of emotional responses to acoustic stimuli. Neuroscience 17, 615-627.

Lee, J.L.C., 2008. Memory reconsolidation mediates the strengthening of memories by additional learning. Nat. Neurosci. 11, 1264-1266.

Lee, J.L.C., Di Ciano, P., Thomas, K.L., Everitt, B.J., 2005. Disrupting reconsolidation of drug memories reduces cocaine seeking behavior. Neuron 47, 795-801.

Lee, J.L.C., Everitt, B.J., 2008. Reactivation-dependent amnesia for appetitive memories is determined by the contingency of stimulus presentation. Learn. Memory 15, 390-393. 
Lee, J.L.C., Everitt, B.J., Thomas, K.L., 2004. Independent cellular processes for hippocampal memory consolidation and reconsolidation. Science 304, 839-843.

Lee, J.L.C., Gardner, R.J., Butler, V.J., Everitt, B.J., 2009. D-cycloserine potentiates the reconsolidation of cocaine-associated memories. Learn. Memory 16, 82-85.

Lee, J.L.C., Milton, A.L., Everitt, B.J., 2006a. Cue-induced cocaine seeking and relapse are reduced by disruption of drug memory reconsolidation. The Journal of Neuroscience 26, 5881-5887.

Lee, J.L.C., Milton, A.L., Everitt, B.J., 2006b. Reconsolidation and extinction of conditioned fear: inhibition and potentiation. The Journal of Neuroscience 26, 10051-10056.

Lewis, D.J., 1979. Psychobiology of active and inactive memory. Psychological Bulletin 86, 1054-1083.

Li, X.F., Stutzmann, G.E., LeDoux, J.E., 1996. Convergent but temporally separated inputs to lateral amygdala neurons from the auditory thalamus and auditory cortex use different postsynaptic receptors: in vivo intracellular and extracellular recordings in fear conditioning pathways. Learn. Memory 3, 229-242.

Liu, X., Weiss, F., 2002. Additive effect of stress and drug cues on reinstatement of ethanol seeking: exacerbation by history of dependence and role of concurrent activation of corticotropin-releasing factor and opioid mechanisms. The Journal of Neuroscience 22, 7856-7861.

Lovibond, P.F., 1983. Facilitation of instrumental behavior by a Pavlovian appetitive conditioned stimulus. Journal of Experimental Psychology. Animal Behavior Processes 9, 225247.

Lu, L., Hope, B.T., Dempsey, J., Liu, S.Y., Bossert, J.M., Shaham, Y., 2005. Central amygdala ERK signaling pathway is critical to incubation of cocaine craving. Nat. Neurosci. 8, 212-219. Lyvers, M., 1998. Drug addiction as a physical disease: the role of physical dependence and other chronic drug-induced neurophysiological changes in compulsive drug selfadministration. Experimental and Clinical Psychopharmacology 6, 107-125.

Ma, D.Y., Xu, M.Y., Yang, H.C., Yang, L.Z., 2008. Effect of inhibition of the central nucleus of the amygdala and drug experience on the regions underlying footshock-induced reinstatement of morphine seeking. The International Journal of Medical Research 36, 9921000.

Mackintosh, N.J., 1974. The Psychology of Animal Learning. Academic Press, London. Maren, S., Aharonov, G., Fanselow, M.S., 1996. Retrograde abolition of conditioned fear after excitotoxic lesions in the basolateral amygdala of rats: absence of a temporal gradient. Behav. Neurosci. 110, 718-726.

Matus-Amat, P., Higgins, E.A., Sprunger, D., Wright-Hardesty, K., Rudy, J.W., 2007. The role of dorsal hippocampus and basolateral amygdala NMDA receptors in the acquisition and retrieval of context and contextual fear memories. Behav. Neurosci. 121, 721-731.

McAuliffe, W.E., 1982. A test of Wikler's theory of relapse: the frequency of relapse due to conditioned withdrawal sickness. The International Journal of the Addictions 17, 19-33. McCrae, F., 2007. Drug addicts told 'kick habit and win an iPod'. The Daily Mail, 26th January. McDonald, A.J., Shammah-Lagnado, S.J., Shi, C., Davis, M., 1999. Cortical afferents to the extended amygdala. Ann. N. Y. Acad. Sci. 877, 309-338.

McElroy, S.L., Weiss, R.D., Mendelson, J.H., Teoh, S.K., McAfee, B., Mello, N.K., 1989. Desipramine treatment for relapse prevention in cocaine dependence. NIDA Research Monograph 95, 57-63.

McFarland, K., Davidge, S.B., Lapish, C.C., Kalivas, P.W., 2004. Limbic and motor circuitry underlying footshock-induced reinstatement of cocaine-seeking behavior. The Journal of Neuroscience 24, 1551-1560.

McGaugh, J.L., 1966. Time-dependent processes in memory storage. Science 153, 13511358. 
McNamara, R., Dalley, J.W., Robbins, T.W., Everitt, B.J., Belin, D., 2010. Trait-like impulsivity does not predict escalation of heroin self-administration in the rat. Psychopharmacology 212, 453-464.

Meil, W.M., See, R.E., 1997. Lesions of the basolateral amygdala abolish the ability of drug associated cues to reinstate responding during withdrawal from self-administered cocaine. Behav. Brain Res. 87, 139-148.

Mello, N.K., Mendelson, J.H., Bree, M.P., Lukas, S.E., 1990. Buprenorphine and naltrexone effects on cocaine self-administration by Rhesus monkeys. The Journal of Pharmacology and Experimental Therapeutics 254, 926-939.

Meredith, G.E., Baldo, B.A., Andrezjewski, M.E., Kelley, A.E., 2008. The structural basis for mapping behavior onto the ventral striatum and its subdivisions. Brain Structure \& Function 213, 17-27.

Milekic, M.H., Brown, S.D., Castellini, C., Alberini, C.M., 2006. Persistent disruption of an established morphine conditioned place preference. The Journal of Neuroscience 26, 30103020.

Miles, F.J., Everitt, B.J., Dickinson, A., 2003. Oral cocaine seeking by rats: action or habit? Behav. Neurosci. 117, 927-938.

Miller, C.A., Marshall, J.F., 2005. Molecular substrates for retrieval and reconsolidation of cocaine-associated contextual memory. Neuron 47, 873-884.

Miller, D.B., Dougherty, J.A., Wikler, A., 1979. Interoceptive conditioning through repeated suppression of morphine-abstinence. II. Relapse-testing. The Pavlovian Journal of Biological Science 14, 170-176.

Milton, A.L., Everitt, B.J., 2009. NMDA receptors and beta-adrenergic receptors as molecular targets for the prevention of relapse to drug-seeking. European Neuropsychopharmacology 19, S86-S87.

Milton, A.L., Everitt, B.J., 2010. The psychological and neurochemical mechanisms of drug memory reconsolidation: implications for the treatment of addiction. Eur. J. Neurosci. 31, 2308-2319.

Milton, A.L., Lee, J.L.C., Butler, V.J., Gardner, R.J., Everitt, B.J., 2008a. Intra-amygdala and systemic antagonism of NMDA receptors prevents the reconsolidation of drug-associated memory and impairs subsequently both novel and previously acquired drug-seeking behaviors. The Journal of Neuroscience 28, 8230-8237.

Milton, A.L., Lee, J.L.C., Everitt, B.J., 2008b. Reconsolidation of appetitive memories for both natural and drug reinforcement is dependent on $\beta$-adrenergic receptors. Learn. Memory 15 , 88-92.

Milton, A.L., Renshaw, M.H., Merlo, E., Macak, M., Kelleher, B.F., Everitt, B.J., unpublished results. Reactivation-dependent amnesia of action-outcome and stimulus-response associations in the rat., In preparation.

Milton, A.L., Schramm, M.J.W., Wawrzynski, J., Gore, F., Oikonomou-Mpegeti, F., Wang, N.Q., Samuel, D., Economidou, D., Everitt, B.J., 2011. Antagonism at NMDA receptors, but not $\beta$-adrenergic receptors, disrupts the reconsolidation of pavlovian conditioned approach and instrumental transfer for ethanol-associated conditioned stimuli. Psychopharmacology, doi: 10.1007/s00213-00011-02399-00219.

Misanin, J.R., Miller, R.R., Lewis, D.J., 1968. Retrograde amnesia produced by electroconvulsive shock after reactivation of a consolidated memory trace. Science 160, 554555.

Mishkin, M., Malamut, B., Bachevalier, J., Lynch, G., McGaugh, J.L., Weinberger, N.M., 1984. Memories and habits: two neural systems, Neurobiol. Learn. Mem. Guilford, New York, pp. 65-77.

Mogenson, G.J., Jones, D.L., Yim, C.Y., 1980. From motivation to action: functional interface between the limbic system and the motor system. Prog. Neurobiol. 14, 69-97. 
Molander, A.C., Mar, A., Norbury, A., Steventon, S., Moreno, M., Caprioli, D., Theobald, D.E.H., Belin, D., Everitt, B.J., Robbins, T.W., Dalley, J.W., 2011. High impulsivity predicting vulnerability to cocaine addiction in rats: some relationship with novelty preference but not novelty reactivity, anxiety or stress. Psychopharmacology 215, 721-731.

Monfils, M.H., Cowansage, K.K., Klann, E., LeDoux, J.E., 2009. Extinction-reconsolidation boundaries: key to persistent attenuation of fear memories. Science 324, 951-955.

Moran, M.M., McFarland, K., Melendez, R.I., Kalivas, P.W., Seamans, J.K., 2005.

Cystine/glutamate exchange regulates metabotropic glutamate receptor presynaptic inhibition of excitatory transmission and vulnerability to cocaine seeking. The Journal of Neuroscience 25, 6389-6393.

Mucha, R.F., Kalant, H., Linseman, M.A., 1979. Quantitative relationships among measures of morphine tolerance and physical dependence in the rat. Pharmacol. Biochem. Behav. 10, 397-405.

Murray, J.E., Belin, D., Everitt, B.J., 2011. Dorsomedial and dorsolateral striatum are doubly dissociated in control over the acquisition and performance of cocaine seeking. Behavioural Pharmacology 22, e28.

Nader, K., 2003. Memory traces unbound. Trends Neurosci. 26, 65-72.

Nader, K., Schafe, G.E., LeDoux, J.E., 2000. Fear memories require protein synthesis in the amygdala for reconsolidation after retrieval. Nature 406, 722-726.

Nelson, A., Killcross, S., 2006. Amphetamine exposure enhances habit formation. The Journal of Neuroscience 26, 3805-3812.

Nic Dhonnchadha, B.A., Kantak, K.M., 2011. Cognitive enhancers for facilitating drug cue extinction: insights from animal models. Pharmacology, Biochemistry, and Behavior 99, 229244.

Nordquist, R.E., Voorn, P., de Mooij-van Malsen, J.G., Joosten, R.N.J.M.A., Pennartz, C.M.A., Vanderschuren, L.J.M.J., 2007. Augmented reinforcer value and accelerated habit formation after repeated amphetamine treatment. European Neuropsychopharmacology 17, 532-540. O'Brien, C.P., Childress, A.R., McClellan, T.A., Ehrman, R., 1992. Classical conditioning in drug dependent humans. Ann. N. Y. Acad. Sci. 654, 400-415.

O'Brien, C.P., Childress, A.R., McLellan, T., Ehrman, R., 1990. Integrating systemic cue exposure with standard treatment in recovering drug dependent patients. Addict. Behav. 15, 355-365.

Olmstead, M.C., Lafond, M.V., Everitt, B.J., Dickinson, A., 2001. Cocaine seeking by rats is a goal-directed action. Behav. Neurosci. 115, 394-402.

Packard, M.G., McGaugh, J.L., 1996. Inactivation of hippocampus or caudate nucleus with lidocaine differentially affects expression of place and response learning. Neurobiol. Learn.

Mem. 65, 65-72.

Parkinson, J.A., Dalley, J.W., Cardinal, R.N., Bamford, A., Fehnert, B., Lachenal, G., Rudarakanchana, N., Halkerston, K.M., Robbins, T.W., Everitt, B.J., 2002. Nucleus accumbens dopamine depletion impairs both acquisition and performance of appetitive pavlovian approach behaviour: implications for mesoaccumbens dopamine function. Behav. Brain Res. $137,149-163$.

Parkinson, J.A., Olmstead, M.C., Burns, L.H., Robbins, T.W., Everitt, B.J., 1999. Dissociation in effects of lesions of the nucleus accumbens core and shell on appetitive pavlovian approach behavior and the potentiation of conditioned reinforcement and locomotor activity by Damphetamine. The Journal of Neuroscience 19, 2401-2411.

Parkinson, J.A., Willoughby, P.J., Robbins, T.W., Everitt, B.J., 2000. Disconnection of the anterior cingulate cortex and nucleus accumbens core impairs pavlovian approach behavior: further evidence for limbic cortical-ventral striatopallidal systems. Behav. Neurosci. 114, 4263. 
Pavlov, I.P., 1927. Conditioned reflexes: an investigation of the physiological activity of the cerebral cortex. Oxford University Press, London.

Pelloux, Y., Everitt, B.J., Dickinson, A., 2007. Compulsive drug seeking by rats under punishment: effects of drug taking history. Psychopharmacology 194, 127-137.

Pert, A., Post, R., Weiss, S.R., 1990. Conditioning as a critical determinant of sensitization induced by psychomotor stimulants. NIDA Research Monograph 97, 208-241.

Petry, N.M., Tedford, J., Austin, M., Nich, C., Carroll, K.M., Rounsaville, B.J., 2004. Prize reinforcement contingency management for treating cocaine absuers: how low can we go, and with whom? Addiction 99, 349-360.

Phillips, R.G., LeDoux, J.E., 1992. Differential contribution of amygdala and hippocampus to cued and contextual fear conditioning. Behav. Neurosci. 106, 274-285.

Piazza, P.V., Deminiere, J.M., Le Moal, M., Simon, H., 1990. Stress- and pharmacologicallyinduced behavioral sensitization increases vulnerability to acquisition of amphetamine selfadministration. Brain Res. 514, 22-26.

Pilla, M., Perachon, S., Sautel, F., Garrido, F., Mann, A., Wermuth, C.G., Schwartz, J.C., Everitt, B.J., Sokoloff, P., 1999. Selective inhibition of cocaine-seeking behaviour by a partial dopamine $D_{3}$ receptor agonist. . Nature 400, 371-375.

Pitkänen, A., Savander, V., LeDoux, J.E., 1997. Organization of intra-amygdaloid circuitries in the rat: an emerging framework for understanding functions of the amygdala. Trends Neurosci. 20, 517-523.

Price, K.L., McRae-Clark, A.L., Saladin, M.E., Maria, M.M., DeSantis, S.M., Back, S.E., Brady, K.T., 2009. D-cycloserine and cocaine cue reactivity: preliminary findings. . The American Journal of Drug and Alcohol Abuse 35, 434-438.

Ramsey, N.F., Van Ree, J.M., 1993. Emotional but not physical stress enhances intravenous cocaine self-administration in drug-naive rats. Brain Res. 608, 216-222.

Redish, A.D., Jensen, S., Johnson, A., 2008. A unified framework for addiction: vulnerabilities in the decision process. Behavioral and Brain Sciences 31, 415-487.

Redish, A.D., Jensen, S., Johnson, A., Kurth-Nelson, Z., 2007. Reconciling reinforcement learning models with behavioral extinction and renewal: implications for addiction, relapse and problem gambling. Psychological Review 114, 784-805.

Rizvi, T.A., Ennis, M., Behbehani, M.M., Shipley, M.T., 1991. Connections between the central nucleus of the amygdala and the midbrain periaqueductal gray: topography and reciprocity. The Journal of Comparative Neurology 303, 121-131.

Robbins, T.W., Everitt, B.J., 1996. Neurobehavioural mechanisms of reward and motivation. Curr. Opin. Neurobiol. 6, 228-236.

Robins, L.N., Davis, D.H., Goodwin, D.W., 1974. Drug use by U.S. army enlisted men in Vietnam: a follow-up on their return home. Am. J. Epidemiol. 99, 235-249.

Robinson, M.J.F., Franklin, K.B.J., 2007a. Central but not peripheral beta-adrenergic antagonism blocks reconsolidation for a morphine place preference. Behav. Brain Res. 182, 129-134.

Robinson, M.J.F., Franklin, K.B.J., 2007b. Effects of anisomycin on consolidation and reconsolidation of a morphine-conditioned place preference. Behav. Brain Res. 178, 146153.

Robinson, M.J.F., Franklin, K.B.J., 2010. Reconsolidation of a morphine place preference: impact of the strength and age of memory on disruption by propranolol and midazolam. Behav. Brain Res. 213, 201-207.

Robinson, T.E., Berridge, K.C., 1993. The neural basis of drug craving: an incentivesensitization theory of addiction. Brain Res. Rev. 18, 247-291.

Robinson, T.E., Berridge, K.C., 2000. The psychology and neurobiology of addiction: an incentive-sensitization view. Addiction 95, 91-117. 
Rösner, S., Leucht, S., Lehert, P., Soyka, M., 2008. Acamprosate supports abstinence, naltrexone prevents excessive drinking: evidence from a meta-analysis with unreported outcomes. J. Psychopharm. 22, 11-23.

Sadler, R., Herzig, V., Schmidt, W.J., 2007. Repeated treatment with the NMDA antagonist MK-801 disrupts reconsolidation of memory for amphetamine-conditioned place preference. Behavioural Pharmacology 18, 699-703.

Sanchez, H., Quinn, J.J., Torregrossa, M.M., Taylor, J.R., 2010. Reconsolidation of a cocaineassociated stimulus requires amygdalar protein kinase $A$. The Journal of Neuroscience 30 , 4401-4407.

Sanchis-Segura, C., Spanagel, R., 2008. Behavioural assessment of drug reinforcement and addictive features in rodents: an overview. Addict. Biol. 11, 2-38.

Santa Ana, E.J., Rounsaville, B.J., Frankforter, T.L., Nich, C., Babuscio, T., Poling, J., Gonsai, K., Hill, K.P., Carroll, K.M., 2009. D-cycloserine attenuates reactivity to smoking cues in nicotine dependent smokers: a pilot investigation. Drug Alcohol Depend. 104, 220-227.

Schiller, D., Monfils, M.H., Raio, C.M., Johnson, D.C., LeDoux, J.E., Phelps, E.A., 2010. Preventing the return of fear in humans using reconsolidation update mechanisms. Nature 463, 49-54.

Schneider, A.M., Sherman, W., 1968. Amnesia: a function of the temporal relation of footshock to electroconvulsive shock. Science 159, 219-222.

Schoenbaum, G., Chiba, A.A., Gallagher, M., 1998. Orbitofrontal cortex and basolateral amygdala encode expected outcomes during learning. Nat. Neurosci. 1, 155-159.

Schoenbaum, G., Esber, G.R., 2010. How do you (estimate you will) like them apples? Integration as a defining trait of orbitofrontal function. Curr. Opin. Neurobiol. 20, 205-211. Schramm, M.J.W., Milton, A.L., Everitt, B.J., unpublished results. The $\beta$-adrenergic receptor antagonist propranolol disrupts the conditioned reinforcing properties of alcohol-associated cues., In preparation.

Schulteis, G., Ahmed, S.H., Morse, A.C., Koob, G.F., Everitt, B.J., 2000. Conditioning and opiate withdrawal. Nature 405, 1013-1014.

Schultz, W., Dayan, P., Montague, P.R., 1997. A neural substrate of prediction and reward. Science 275, 1593-1599.

Selden, N.R.W., Everitt, B.J., Jarrard, L.E., Robbins, T.W., 1991. Complementary roles for the amygdala and hippocampus in aversive conditioning to explicit and contextual cues.

Neuroscience 42, 335-350.

Shaham, Y., Shalev, U., Lu, L., de Wit, H., Stewart, J., 2003. The reinstatement model of drug relapse: history, methodology and major findings. Psychopharmacology 168, 3-20.

Shippenberg, T.S., Heidbreder, C., 1995. Sensitization to the conditioned rewarding effects of cocaine: pharmacological and temporal characteristics. The Journal of Pharmacology and Experimental Therapeutics 273, 808-815.

Siegel, S., 1975. Evidence for rats that morphine tolerance is a learned response. Journal of Comparative Physiology and Psychology 89, 498-506.

Siegel, S., 1977. Morphine tolerance acquisition as an associative process. J. Exp. Psychol.:

Anim. Behav. Processes 3, 1-13.

Silverman, K., Wong, C.J., Higgins, S.T., Brooner, R.K., Montoya, I.D., Contoreggi, C., Umbricht-Schneiter, A., Schuster, C.R., Preston, K.L., 1996. Increasing opiate abstinence through voucher-based reinforcement therapy. Drug Alcohol Depend. 41, 157-165.

Simms, J.A., Steensland, P., Medina, B., Abernathy, K.E., Chandler, L.J., Wise, R., Bartlett, S.E., 2008. Intermittent access to $20 \%$ ethanol induces high ethanol consumption in Long-Evans and Wistar rats. Alcoholism: Clinical and Experimental Research 32, 1816-1823.

Sinha, R., Fuse, T., Aubin, L.R., O'Malley, S.S., 2000. Psychological stress, drug-related cues and cocaine craving. Psychopharmacology 152, 140-148.

Skinner, B.F., 1938. The behavior of organisms. Appleton-Century-Crofts., New York. 
Solomon, R.L., Corbit, J.D., 1974. An opponent-process theory of motivation: I. Temporal dynamics of affect. Psychological Review 81, 119-145.

Stewart, J., de Wit, H., Eikelboom, R., 1984. Role of unconditioned and conditioned drug effects in the self-administration of opiates and stimulants. Psychological Review 91, 251268.

Stolerman, I.P., Fink, R., Jarvik, M.E., 1973. Acute and chronic tolerance to nicotine measured by activity in rats. Psychopharmacologia 30, 329-342.

Streatfeild, D., 2007. Cocaine: a definitive history. Virgin Books, London.

Thanos, P.K., Bermeo, C., Wang, G.J., Volkow, N.D., 2009. D-cycloserine accelerates the extinction of cocaine-induced conditioned place preference in $\mathrm{C} 57 \mathrm{bL} / \mathrm{c}$ mice. Behav. Brain Res. 199, 345-349.

Théberge, F.R., Milton, A.L., Belin, D., Lee, J.L.C., Everitt, B.J., 2010. The basolateral amygdala and nucleus accumbens core mediate dissociable aspects of drug memory reconsolidation. Learn. Memory 17, 444-453.

Thomas, K.L., Hall, J., Everitt, B.J., 2002. Cellular imaging with zif268 expression in the rat nucleus accumbens and frontal cortex further dissociates the neural pathways activated following the retrieval of contextual and cued fear memory. Eur. J. Neurosci. 16, 1789-1796. Thorndike, E.L., 1911. Animal intelligence: experimental studies. Macmillan, New York. Tiffany, S.T., 1990. A cognitive model of drug urges and drug-use behavior: role of automatic and nonautomatic processes. Psychological Review 97, 147-168.

Tomie, A., 1996. Locating reward cue at response manipulandum (CAM) induces symptoms of drug abuse. Neurosci. Biobehav. Rev. 20, 505-535.

Torregrossa, M.M., Sanchez, H., Taylor, J.R., 2010. D-cycloserine reduces the context specificity of pavlovian extinction of cocaine cues through actions in the nucleus accumbens. The Journal of Neuroscience 30, 10526-10533.

Tronson, N.C., Taylor, J.R., 2007. Molecular mechanisms of memory reconsolidation. Nature Reviews Neuroscience 8, 262-275.

Trujillo, K.A., Akil, H., 1991. Inhibition of morphine tolerance and dependence by the NMDA receptor antagonist MK-801. Science 251, 85-87.

Turner, B.H., Herkenham, M., 1991. Thalamoamygdaloid projections in the rat: a test of the amygdala's role in sensory processing. The Journal of Comparative Neurology 313, 295-325. Tyacke, R.J., Lingford-Hughes, A., Reed, L.J., Nutt, D.J., 2010. GABA $A_{B}$ receptors in addiction and its treatment. Advances in Pharmacology 58, 373-396.

Valjent, E., Corbillé, A.G., Bertran-Gonzelez, J., Hervé, D., Girault, J.A., 2006. Inhibition of ERK pathway or protein synthesis during reexposure to drugs of abuse erases previously learned place preference. Proceedings of the National Academy of Sciences 103, 2932-2937.

van Dongen, Y.C., Deniau, J.M., Pennartz, C.M., Galis-de Graaf, Y., Voorn, P., Thierry, A.M., Groenewegen, H.J., 2005. Anatomical evidence for direct connections between the shell and core subregions of the rat nucleus accumbens. Neuroscience 136, 1049-1071.

Vanderschuren, L.J.M.J., Di Ciano, P., Everitt, B.J., 2005. Involvement of the dorsal striatum in cue-controlled cocaine seeking. The Journal of Neuroscience 25, 8665-8670.

Vanderschuren, L.J.M.J., Everitt, B.J., 2004. Drug seeking becomes compulsive after prolonged cocaine self-adminstration. Science 305, 1017-1019.

Vanderschuren, L.J.M.J., Everitt, B.J., 2005. Behavioral and neural mechanisms of compulsive drug seeking. Eur. J. Pharmacol. 526, 77-88.

Veeneman, M.M.J., Broekhoven, M.H., Damsteegt, R., Vanderschuren, L.J.M.J., 2012. Distinct contributions of dopamine in the dorsolateral striatum and nucleus accumbens shell to the reinforcing properties of cocaine. Neuropsychopharmacology 37, 487-498.

Vengeliene, V., Kiefer, F., Spanagel, R., 2008. D-cycloserine facililtates extinction of conditioned alcohol-seeking behaviour in rats. Alcohol \& Alcoholism 43, 626-629. 
von der Goltz, C., Vengeliene, V., Bilbao, A., Perreau-Lenz, S., Pawlak, C.R., Kiefer, F., Spanagel, R., 2009. Cue-induced alcohol seeking behaviour is reduced by disrupting the reconsolidation of alcohol-related memories. Psychopharmacology 205, 389-397.

Walker, D.L., Ressler, K.J., Lu, K.T., Davis, M., 2002. Facilitation of conditioned fear extinction by systemic administration or intra-amygdala infusions of D-cycloserine as assessed with fear-potentiated startle in rats. The Journal of Neuroscience 22, 2343-2351.

Wang, S.H., Ostlund, S.B., Nader, K., Balleine, B.W., 2005. Consolidation and reconsolidation of incentive learning in the amygdala. The Journal of Neuroscience 25, 830-835.

Whitelaw, R.B., Markou, A., Robbins, T.W., Everitt, B.J., 1996. Excitotoxic lesions of the basolateral amygdala impair the acquisition of cocaine-seeking behaviour under a secondorder schedule of reinforcement. Psychopharmacology 127, 213-224.

Wikler, A., 1948. Recent progress in research on the neurophysiologic basis of morphine addiction. Am. J. Psychiatry 105, 329-338.

Wikler, A., Pescor, F.T., 1967. Classical conditioning of a morphine abstinence phenomenon, reinforcement of opioid-drinking behavior and "relapse" in morphine-addicted rats.

Psychopharmacologia 10, 255-284.

Wise, R.A., 2002. Brain reward circuitry: insights from unsensed incentives. Neuron 36, 229240.

Wise, R.A., Leeb, K., 1993. Psychomotor-stimulant sensitization: a unitary phenomenon? Behavioural Pharmacology 4, 339-349.

Wouda, J.A., Diergaarde, L., Riga, D., Van Mourik, Y., Schoffelmeer, A.N.M., De Vries, T.J., 2010. Disruption of long-term alcohol-related memory reconsolidation: role of $\beta$ adrenoceptors and NMDA receptors. Frontiers in Behavioral Neuroscience 4, 179. doi: 110.3389/fnbeh.2010.00179.

Yamada, H., Bruijnzeel, A.W., 2010. Stimulation of $\alpha_{2}$-adrenergic receptors in the central nucleus of the amygdala attenuates stress-induced reinstatement of nicotine seeking in rats. Neuropharmacology 60, 303-311.

Yin, H.H., Knowlton, B.J., Balleine, B.W., 2004. Lesions of dorsolateral striatum preserve outcome expectancy but disrupt habit formation in instrumental learning. Eur. J. Neurosci. 19, 181-189.

Yin, H.H., Knowlton, B.J., Balleine, B.W., 2006. Inactivation of dorsolateral striatum enhances sensitivity to changes in the action-outcome contingency in instrumental conditioning. Behav. Brain Res. 166, 189-196.

Yin, H.H., Ostlund, S.B., Knowlton, B.J., Balleine, B.W., 2005. The role of the dorsomedial striatum in instrumental conditioning. Eur. J. Neurosci. 22, 513-523.

Zahm, D.S., 1999. Functional-anatomical implications of the nucleus accumbens core and shell subterritories. Ann. N. Y. Acad. Sci. 877, 113-128.

Zahm, D.S., Brog, J.S., 1992. On the significance of subterritories in the "accumbens" part of the rat ventral striatum. Neuroscience 50, 751-767.

Zapata, A., Minney, V.L., Shippenberg, T.S., 2010. Shift from goal-directed to habitual cocaine seeking after prolonged experience in rats. The Journal of Neuroscience 30, 15457-15463.

\section{FIGURE CAPTIONS}

Figure 1. The limbic corticostriatal circuitry implicated in drug addiction. Blue arrows,

glutamatergic projections; red arrows, dopaminergic projections; pink arrows, GABAergic

projections; Acb, nucleus accumbens; BLA, basolateral amygdala; $\mathrm{CeN}$, central nucleus of the 
amygdala; VTA, ventral tegmental area; SNc, substantia nigra pars compacta. GP, globus pallidus ( $D$, dorsal; V, ventral). Reproduced, with permission, from Koob, Everitt \& Robbins (2008).

Figure 2. Zif268 levels increase in the posterior dorsolateral striatum following retrieval of a stimulus-response, 'habit' memory. (A) Maze procedure adapted from Packard \& McGaugh (1996). Rats were trained to retrieve a sucrose pellet reward from a particular location over an extended period of time (14 sessions). On the probe test day, the maze was rotated $180^{\circ}$ and entry into one arm was allowed. The arm that was entered was used to classify rats as using an A-O or S-R association to complete the task. (B) Levels of Zif268 expression were analysed using western blotting in the anterior dorsomedial striatum (aDMS), the anterior dorsolateral striatum (aDLS), the posterior dorsomedial striatum ( $p D M S$ ) and the posterior dorsolateral striatum ( $p D L S)$. Levels of Zif268 expression in the $p D L S$ were markedly higher in animals that retrieved the S-R memory (black bars; $n=4$ ) in the probe test $2 \mathrm{hrs}$ before killing, as compared to animals that were killed $6 \mathrm{hrs}$ after the probe test $(\boldsymbol{n}=\mathbf{5})$, and those animals that retrieved the action-outcome (place) memory during the probe test (white bars, $\boldsymbol{n}=\mathbf{1}$ in the $\mathbf{2 h r}$ group, $\boldsymbol{n}=\mathbf{4}$ in the $6 \mathrm{hr}$ group; Group: $F(3$, $9)=7.60, p<0.05)$. There were no differences in the level of Zif268 expression in the $p D M S$ (Group: $F(3,10)=1.36, p=0.33$ ), in the $\operatorname{aDLS}$ (Group: $F<1$ ) or in the $\operatorname{aDMS}$ (Group: $F(3,10)=$ $2.53, p=0.14)$. 
TABLES

\begin{tabular}{|l|}
\hline \multicolumn{1}{c|}{ DSM-IVR } \\
\hline - \\
- Substance is often taken in larger amounts \\
or over a longer period than intended \\
Persistent desire or unsuccessful efforts to \\
cut down or control substance use \\
Persistence despite negative consequences \\
Continued substance use despite knowledge \\
of having a persistent or recurrent \\
psychological or physical problem that is \\
caused or exacerbated by use of the \\
substance
\end{tabular}

\section{High motivation to take drug}

- A great deal of time is spent in activities necessary to obtain the substance, use the substance, or recover from its effects

- Important social, occupational or recreational activities given up or reduced because of substance abuse

\section{Physiological adaptations}

- Tolerance, as defined by either a need for increasing amounts of the substance in order to achieve intoxication or desired effect, or a markedly diminished effect with continued use of the same amount

- Withdrawal, as manifested by either a characteristic withdrawal syndrome for the substance, or the same (or closely related) substance is taken to relieve or avoid withdrawal symptoms
Loss of control

- Difficulties in controlling substance-taking behaviour in terms of its onset, termination or levels of use

- A strong desire or sense of compulsion to take the substance

\section{Persistence despite negative consequences}

- Persisting with substance use despite clear evidence of overtly harmful consequences, depressive mood states consequent to heavy use, or drug related impairment of cognitive functioning

\section{High motivation to take drug}

- Progressive neglect of alternative pleasures or interests because of psychoactive substance use, increased amount of time necessary to obtain or take substance or to recover from its effects

\section{Physiological adaptations}

- Evidence of tolerance, such that increased doses of the psychoactive substance are required in order to achieve effects originally produced by lower doses

- A physiological withdrawal state when substance use has ceased or been reduced, as evidenced by the characteristic withdrawal syndrome for the substance, or use of the same (or a closely related) substance with the intention of relieving or avoiding withdrawal symptoms

Table 1. Definition of 'substance dependence' according to DSM-IVR and ICD10. 


\begin{tabular}{|c|c|}
\hline Term & Definition \\
\hline Autoshaping & $\begin{array}{l}\text { The behavioural procedure in which pavlovian conditioned } \\
\text { approach is induced to a stimulus. See PAVLOVIAN } \\
\text { CONDITIONED APPROACH. }\end{array}$ \\
\hline Conditioned motivation & $\begin{array}{l}\text { The process by which a pavlovian CONDITIONED STIMULUS can } \\
\text { enhance an instrumental response through its appetitive } \\
\text { motivational properties. This can be reinforcer-specific (i.e. } \\
\text { a pavlovian CS that predicts the delivery of a particular } \\
\text { reinforcer can enhance instrumental responding for that } \\
\text { reinforcer, which has been learned separately) or general } \\
\text { (i.e. the CS enhances instrumental responding through its } \\
\text { motivationally activating effects on behaviour). }\end{array}$ \\
\hline Conditioned reinforcement & $\begin{array}{l}\text { The process by which a pavlovian CS acquires secondary, or } \\
\text { conditioned, reinforcing properties that allow it to support } \\
\text { instrumental responding over delays to primary } \\
\text { reinforcement, and the acquisition of new instrumental } \\
\text { responses. }\end{array}$ \\
\hline Conditioned response (CR) & $\begin{array}{l}\text { In PAVLOVIAN CONDITIONING, a response that is elicited by } \\
\text { presentation of the CONDITIONED STIMULUS. This can be the } \\
\text { same, or different, from the UNCONDITIONED RESPONSE. }\end{array}$ \\
\hline Conditioned stimulus (CS) & $\begin{array}{l}\text { In PAVLOVIAN CONDITIONING, a previously motivationally } \\
\text { neutral stimulus that is aSSOciated with an UNCONDITIONED } \\
\text { STIMULUS or a REINFORCER. }\end{array}$ \\
\hline Conditioned suppression & $\begin{array}{l}\text { The capacity of an aversive pavlovian CONDITIONED STIMULUS } \\
\text { to suppress ongoing instrumental responding. }\end{array}$ \\
\hline Conditioned withdrawal & $\begin{array}{l}\text { Particularly for drugs of abuse that produce physiological } \\
\text { tolerance and withdrawal, the phenomenon by which } \\
\text { contexts and discrete pavlovian CONDITIONED STIMULI become } \\
\text { associated with the drug withdrawal state, and so elicit } \\
\text { withdrawal symptoms when they are presented. }\end{array}$ \\
\hline $\begin{array}{l}\text { Goal-directed (A-O) } \\
\text { association }\end{array}$ & $\begin{array}{l}\text { In INSTRUMENTAL CONDITIONING, the association by which an } \\
\text { action that produces a particular outcome (or goal state) is } \\
\text { represented. Responses are elicited depending upon the } \\
\text { representation of the outcome, so that if the outcome is } \\
\text { devalued then the action will not be elicited. }\end{array}$ \\
\hline Habit (S-R) association & $\begin{array}{l}\text { In INSTRUMENTAL CONDITIONING, the association by which a } \\
\text { pavlovian CONDITIONED STIMULUS elicits a response, which is } \\
\text { independent of the representation of the outcome. If } \\
\text { responding is habitual then it will be maintained, even if the } \\
\text { outcome of the action / response has been devalued. } \\
\text { Habitual responding is typically seen following overtraining, } \\
\text { or training in which the contingency between the response } \\
\text { and the outcome is degraded (e.g. variable interval }\end{array}$ \\
\hline
\end{tabular}




\begin{tabular}{|c|c|}
\hline & schedules). \\
\hline Instrumental conditioning & $\begin{array}{l}\text { A type of learning in which the outcome is dependent upon } \\
\text { the behaviour of the individual. Learning can occur through } \\
\text { POSITIVE REINFORCEMENT, NEGATIVE REINFORCEMENT or } \\
\text { PUNISHMENT. }\end{array}$ \\
\hline Negative reinforcement & $\begin{array}{l}\text { A type of INSTRUMENTAL CONDITIONING procedure in which a } \\
\text { particular behaviour is increased in frequency due to the } \\
\text { avoidance of an aversive outcome. }\end{array}$ \\
\hline $\begin{array}{l}\text { Pavlovian conditioned } \\
\text { approach }\end{array}$ & $\begin{array}{l}\text { The process by which a pavlovian CONDITIONED STIMULUS } \\
\text { acquires reinforcing properties that promote approach } \\
\text { towards that CONDITIONED STIMULUS, and often responses that } \\
\text { are appropriate to the primary reinforcer (e.g. rats gnawing } \\
\text { a stimulus that has been paired with food). }\end{array}$ \\
\hline Pavlovian conditioning & $\begin{array}{l}\text { A type of learning in which a previously motivationally } \\
\text { neutral CONDITIONED STIMULUS is paired in Space and time with } \\
\text { a motivationally relevant UNCONDITIONED STIMULUS. The } \\
\text { behaviour of the individual does not affect the contingency } \\
\text { between the presentation of the two stimuli. }\end{array}$ \\
\hline $\begin{array}{l}\text { Pavlovian-instrumental } \\
\text { transfer }\end{array}$ & $\begin{array}{l}\text { The behavioural procedure with which CONDITIONED } \\
\text { MOTIVATION can be assessed. Animals are trained separately } \\
\text { on an INSTRUMENTAL association and a PAVLOVIAN association } \\
\text { for the same REINFORCER. At test, the animals are allowed to } \\
\text { make the instrumental response in the presence of the } \\
\text { pavlovian stimulus, which is a direct test of conditioned } \\
\text { motivation (without the pavlovian stimulus acting to } \\
\text { induce retrieval of the instrumental action representation). } \\
\text { See CONDITIONED MOTIVATION. }\end{array}$ \\
\hline Positive reinforcement & $\begin{array}{l}\text { A type of INSTRUMENTAL CONDITIONING procedure in which a } \\
\text { particular behaviour is increased in frequency due to an } \\
\text { appetitive outcome. }\end{array}$ \\
\hline Punishment & $\begin{array}{l}\text { A type of INSTRUMENTAL CONDITIONING procedure in which a } \\
\text { particular behaviour is decreased in frequency due to an } \\
\text { aversive outcome. }\end{array}$ \\
\hline Reinforcer / reinforcement & $\begin{array}{l}\text { A stimulus that alters the probability of an action or } \\
\text { response being elicited subsequently. This concept does not } \\
\text { assume that the reinforcer produces any hedonic response } \\
\text { in the individual. }\end{array}$ \\
\hline Reward & A stimulus that induces hedonic pleasure. \\
\hline Unconditioned response (UR) & $\begin{array}{l}\text { In PAVLOVIAN CONDITIONING, a response that is elicited by } \\
\text { presentation of an UNCONDITIONED STIMULUS. }\end{array}$ \\
\hline
\end{tabular}


\begin{tabular}{|l|l} 
Unconditioned stimulus (US) & $\begin{array}{l}\text { In PAVLOVIAN CONDITIONING, a stimulus that is motivationally } \\
\text { relevant to the individual (e.g. food, sex) }\end{array}$
\end{tabular}

Table 2. Definitions of specialised psychological terms. Each is appears in small capitals in the text at its first appearance. 


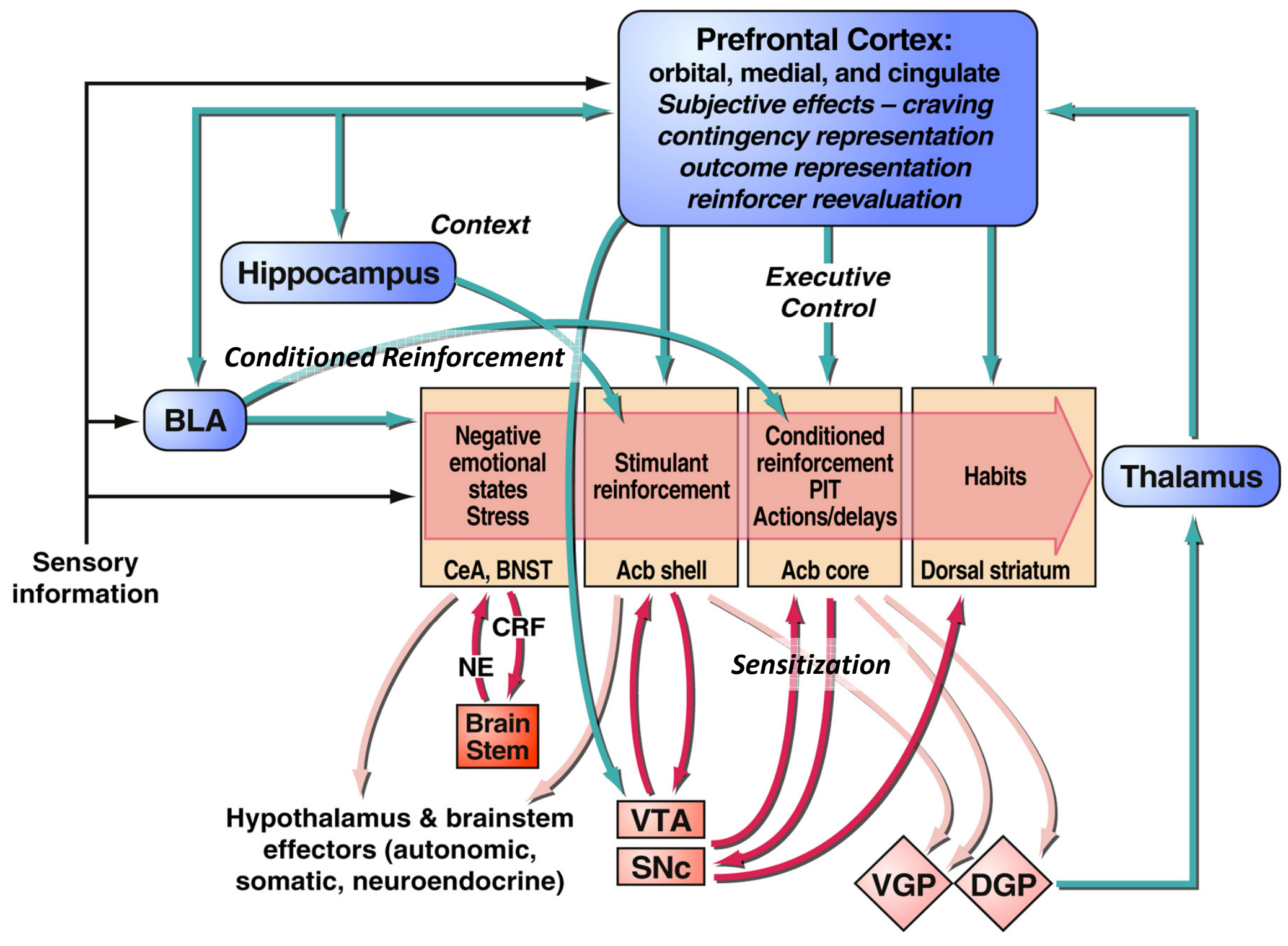




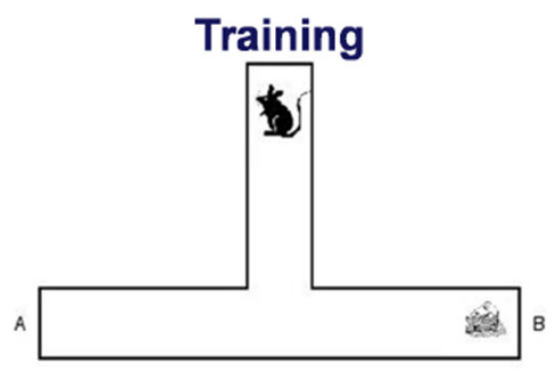

B

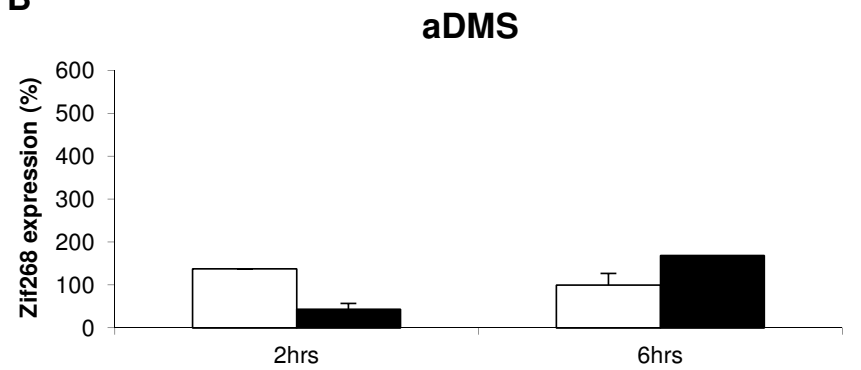

aDLS

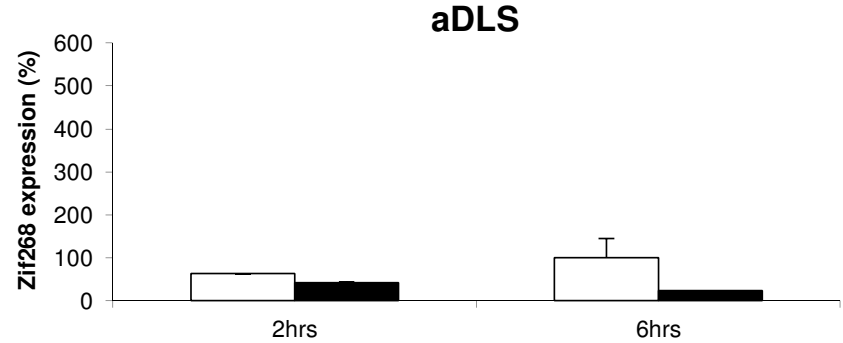

Reactivation

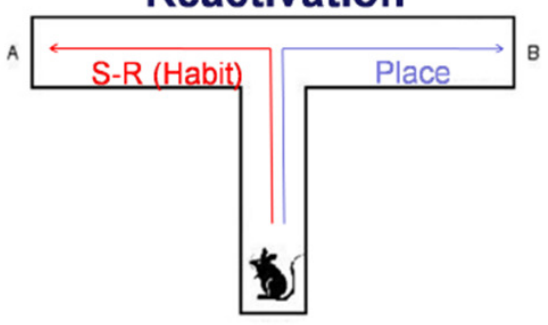

pDMS

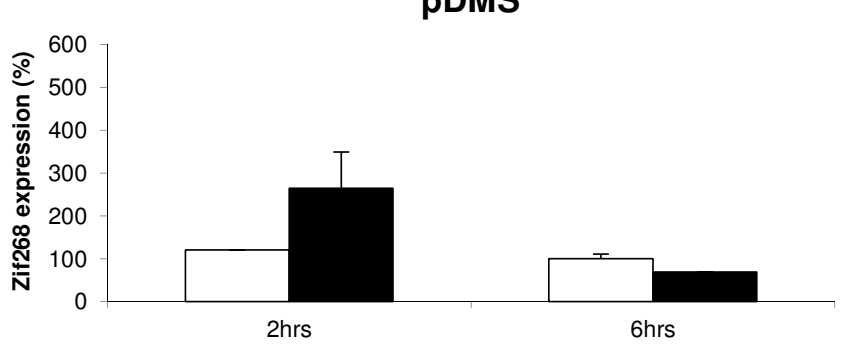

pDLS

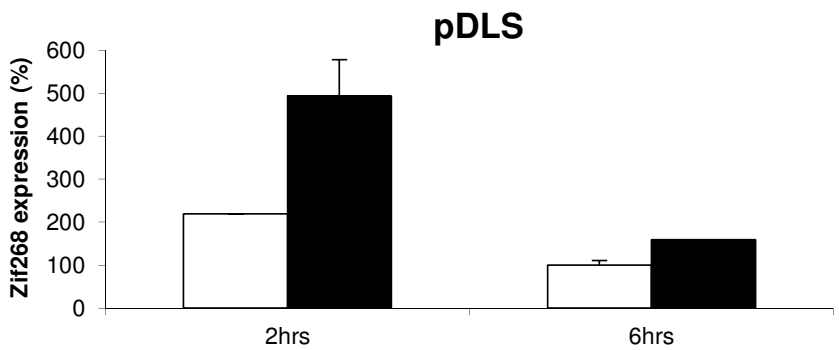

